\title{
El desplazamiento de prácticas impresas y la apropiación de prácticas digitales. Un estudio con alumnos del bachillerato tecnológico aprendiendo a usar la computadora en la escuela*
}

\author{
Laura Macrina Gómez Espinoza \\ Departamento de Investigaciones Educativas, \\ Centro de Investigación y de Estudios Avanzados del Instituto Politécnico Nacional, México
}

\section{Introducción}

Se aprecia en la literatura actual una discusión alrededor de las semejanzas y diferencias entre los textos digitales y los impresos, y de como los primeros transforman las prácticas de lectura y escritura. En cuanto a los textos y sus características, se detecta un continuo de distintas posiciones sobre el auge que tiene la comunicación mediada por la computadora en contraste con el texto impreso (Dorr, 1994; Kalman, 2000). En un extremo se ubican quienes consideran que las nuevas tecnologías de la información y la comunicación (TIC) simplemente constituyen un formato más para la lectura y la escritura, el cual se suma a otros ya existentes. Salomon (1993a), por ejemplo, propone que las TIC únicamente son herramientas que

* Investigación realizada mediante una beca para estudios doctorales otorgada por el Consejo Nacional de Ciencia y Tecnología, México ( ${ }^{\circ}$ registro 162589). Mis agradecimientos a mi tutora, Dra. Judith Kalman, y a los alumnos, maestros y directivos del CETIS \# 154. potencian habilidades ya existentes en el usuario y que éstas no transforman de manera alguna las prácticas lectoescritoras. En el otro extremo desfilan quienes en su mayoría predicen, entre otras cosas, el fin del libro, mismo que tarde o temprano será desplazado por las opciones electrónicas. También consideran que las prácticas de lengua escrita ${ }^{1}$ son básicamente acompañantes de las TIC, y estas últimas son entendidas como tecnologías radicalmente

${ }^{1}$ David Barton (1994, p. 37) se refiere a "prácticas de lengua escrita" y las define como "prácticas sociales asociadas a la letra impresa". Por su parte, Street (1984, p. 1) al referirse a éstas, incluye tanto lo que se hace al utilizar la lectura y/o la escritura como a su conceptualización e ideología, es decir, las creencias e ideas que los lectores y escritores tienen acerca de estas actividades. Las prácticas de lengua escrita son las formas culturales generales de utilizar la lectura y la escritura, cuando la gente participa en un evento de lengua escrita. En adelante se utilizarán indistintamente términos como lengua o cultura escrita, lectura y escritura, o lectoescritura, teniendo en todos los casos el mismo referente. 
El desplazamiento de prácticas impresas y la apropiación de prácticas digitales

distintas y poco relacionadas con las ya existentes (Hynes, 1998).

En relación con las prácticas de lectura y escritura, también hay una variedad de posturas. Por un lado están aquéllos que piensan que la aportación más importante de las TIC es la rapidez que la conectividad da a la búsqueda de información. Yagelski (2000) recabó opiniones de maestros acerca de cómo los jóvenes utilizan la computadora para recopilar información; éstos señalaron que la virtud de esta tecnología era fundamentalmente la velocidad con la que es posible realizar ciertas tareas de investigación y redacción: la consideraron básicamente como una máquina que facilita la ubicación de información y la producción de documentos limpios y ordenados, "bien presentados".

Sin embargo hay quienes arguyen que lo que los estudiantes hacen poco o nada tiene que ver con las prácticas de lectoescritura que se realizaban en la época en la que no se utilizaban las computadoras de forma generalizada. Desde esta posición, Selfe y Hilligoss (1994) sostienen que las nuevas tecnologías cambian la manera de comunicarnos, irrumpen física e intelectualmente nuestra forma de significar, leer, escribir e interpretar textos porque, según estos autores, la naturaleza de los textos, del lenguaje, de la lectoescritura, en sí mismos, están sufriendo transformaciones, puesto que las computadoras están reformulando los entornos en los que se aprende, produce y practica el lenguaje. En este sentido, Costanzo (1994) explica que el lenguaje en la pantalla es distinto al del texto, ya que la posibilidad de crear palabras se extiende, o bien desaparece, a través del espacio limitado de la pantalla. Esto es, debido al tamaño y forma de la pantalla, sólo segmentos de palabras pueden verse a la vez, lo que dificulta el ubicarnos en el espacio del texto electrónico; en lugar de hojear páginas, buscar información apoyándonos en la vista y coordinar movimientos ojos-manos, al leer texto electrónico nos movemos presionando teclas, leyendo línea por línea y pantalla por pantalla, y nuestros movimientos a través del texto están digitalmente controlados mediante comandos precisos del teclado, haciendo que ojos y manos trabajen en forma significativamente diferente. Además, los convencionalismos en materiales impresos tales como sangrías, márgenes, títulos, paginación etc., son ampliados o remplazados por nuevos convencionalismos. La escritura también es diferente ya que, al no requerirse una copia permanente de cada versión de un mismo texto, las computadoras desdibujan los límites entre los borradores y un texto final, de manera que los escritos se generan casi como en una especie de evolución; y al poder alterar la apariencia del texto a través de un diferente formateo, ver las mismas palabras en una nueva configuración con sólo apretar algunas teclas, y el producir movimiento en los textos y transformaciones textuales con teclas de control y de funciones, de insertar, borrar y flechas, la pantalla entonces tiene el poder de distanciar a los escritores de sus textos. También el hecho de que la computadora hace poner especial atención a los aspectos visuales del texto produce que los escritores se entretengan con los tipos y tamaños de letra, y experimenten con los espacios probando los márgenes, justificando las líneas o centrando bloques de información.

Desde una perspectiva sociocultural de la cultura escrita, se asume que leer y escribir sólo pueden ser entendidos como una práctica social que adquiere sentido dentro del contexto social, cultural, político, económico e histórico en el que tiene lugar (Lankshear, Snyder \& Green, 2000; Street, 1984). Leer y escribir son acciones vinculadas a un momento social específico, donde el contexto está constituido por la interacción entre los participantes, la situación en la cual la interacción ocurre, y por los antecedentes históricos y sociales de lo que hacen (Kalman, 2000). En este sentido, el término cultura escrita o literacy podría suplirse por literacies, que sería más adecuado, puesto que se refiere a diversas formas de participar en actividades en las que la letra está involucrada. Es decir, existen diferentes contextos de práctica o prácticas sociales en las que se involucra la producción o interpretación de textos, sean éstos impresos o digitales (Gee, 1996; Lankshear, Snyder \& Green, 2000; Street, 1984, 1999, 2005). 
Al revisar la literatura sobre leer y escribir utilizando las TIC, se aprecia que los estudios sobre los procesadores de texto son los que más se han realizado desde los años ochenta, tratando de reconocer si la computadora puede usarse de una manera que favorezca las habilidades de lectoescritura. Uno de los primeros estudios fue el conducido por Richard Collier en 1983 (apud Hawisher \& Selfe, 1998) con estudiantes de enfermería, en el que se deseaba explorar cómo el uso de un procesador de texto influía en el transcurso de la elaboración de un escrito. Aunque los resultados no evidenciaron mejoría alguna en la calidad del texto producido, sí en cambio revelaron que los escritores elaboraban textos más extensos y recurrían más veces a su revisión durante el proceso, en contraste con quienes escribían con el uso de herramientas convencionales de escritura.

Otro estudio acerca del uso de la computadora es el conducido por Jones en 1994. Labbo y Kuhn (1998) lo refieren, explicando que en este estudio realizado en un taller de escritura se examina el habla y las interacciones sociales de díadas de estudiantes. Los hallazgos sugieren que las historias creadas con ayuda del procesador de texto fueron estructuralmente más cohesivas y léxicamente más elaboradas, en comparación con aquéllas escritas con papel y lápiz. Labbo y Kuhn también reportan un estudio que llevaron a cabo con niños preescolares, acerca de la forma en que aprenden lo que es la lengua escrita, mediante la expresión de sus ideas utilizando la computadora como "herramienta para hacer símbolos". Los niños de su estudio se centraron en la pantalla como el principal escenario en el que tanto la acción como el pensamiento se llevan a cabo, a través del arte, el juego y la escritura. En este estudio se encontró un nexo entre el habla de los pequeños, el tipo de símbolos que creaban, y las características y operaciones de la computadora empleados en el proceso de crear símbolos electrónicos, sugiriendo que estos niños pequeños desarrollaron una comprensión y expectativas de que la computadora es una herramienta comunicativa, para expresar de distintos modos lo que ellos quieren decir. Asimismo, observaron que el trabajo conjunto en la computadora propiciaba un habla metacognitiva entre los participantes, con lo que se corroboran hallazgos en investigaciones similares (Labbo, 1996; Sulzby, 1986).

Estudios etnográficos en este ámbito demuestran que quienes escriben utilizando papel y lápiz lo hacen generalmente de forma silente y en privado; en cambio, quienes utilizan las TIC, transforman el área de trabajo en una actividad pública, con estudiantes reunidos alrededor de las computadoras, leyendo y conversando sobre sus escritos (Hawisher \& Selfe, 1998).

Hay otra serie de estudios sobre hipertexto e hipermedia que se han enfocado en cómo es que los usuarios se desplazan a través de grandes y complejos cuerpos de información presentados en forma no lineal, sin perder su sentido de conectividad. Tratan asimismo de identificar formas de presentar la información de manera que se optimice el aprendizaje, buscando subsanar problemas pedagógicos particulares, al tratar contenidos tradicionalmente difíciles utilizando ahora ambientes hipertextuales. En esta vertiente, algunas investigaciones sugieren que el recurso del hipertexto y los entornos hipermedia pueden propiciar una comprensión más profunda de contenidos o materiales de lectura difíciles, en comparación con el uso de escenarios educativos tradicionales (Spiro \& Jehng, 1990). También se ha encontrado evidencia de que los entornos hipermedia favorecen la comprensión lectora en alumnos con bajo nivel de lectoescritura (Anderson-Inman \& Horney, 1998), e impulsan a los estudiantes a escribir sus hipertextos, haciendo que lectores y escritores realicen sus propias conexiones de información (Kaplan \& Moulthrop, 1991); estos hallazgos sugieren que este tipo de escenario puede constituir un nuevo medio instruccional que valdría seguir explorando.

En los años recientes ha habido un amplio desarrollo en el uso de las TIC en educación. En el campo de la escritura, Anderson (2001) reporta un estudio etnográfico con alumnos de secundaria pertenecientes a un grupo minoritario con bajo rendimiento escolar. En este estudio sobre composición 
escrita utilizando las TIC, los alumnos manifiestan que el construir y publicar su propia página Web les ayudó a desarrollar sus habilidades de lectura y escritura, al poder elegir y escribir los contenidos de su interés, diseñar por sí mismos su página y teclear su texto. En el proceso, tuvieron la oportunidad de mostrar creatividad, aprender palabras, mejorar su ortografía, además de desarrollar nuevas habilidades computacionales y aprender en forma divertida. El estudio confirma, por otra parte, la noción de que al escribir conjuntamente utilizando la computadora, se promueve un interés real por los progresos entre sí de los alumnos, motivando una ayuda mutua en las formas de escribir, en la ortografía, así como en aspectos más operativos, ya que los alumnos se ofrecen apoyo uno al otro cuando ocurre un error en el trabajo, olvidos al salvar la información o equivocaciones al operar el sistema. El autor concluye que las TIC no deben ser entendidas como un fin en sí mismo, sino como una herramienta que debe desplegarse en forma flexible, conforme a necesidades específicas, dentro de un contexto de aprendizaje claramente definido.

Por otra parte, Cassany (2003a) establece que la paulatina migración de la escritura impresa a la electrónica se está produciendo desde hace unos veinte años, y es todavía un proceso en curso que depende estrechamente del permanente desarrollo tecnológico. Para este autor, definitivamente el cambio más evidente es la aparición de géneros discursivos nuevos como el chat y el correo electrónico con formas lingüísticas particulares, donde los contextos comunicativos globales han modificado sustancial-mente las prácticas sociales de comunicación. También señala que las implicaciones pedagógicas pueden ubicarse en tres ámbitos. Uno de ellos es en los objetivos e instrumentos de aprendizaje; en este campo hay estudios que describen prácticas de escritura escolares y extraescolares en las que la computadora constituye un elemento motivador para el alumnado (e.g. Nájera, 2001). El segundo se refiere a los contextos educativos, es decir, la conformación de centros virtuales y tutoriales en línea que posibilitan, por ejemplo, la revisión de escritos entre pares a través de opciones como listas, foros, chats y amigos por correspondencia electrónica, entre otros. El último ámbito se refiere a programas de aprendizaje de cómo hacer composiciones escritas; en este ámbito existen numerosos programas informáticos que asisten al escritor cuya contribución principal es desarrollar la lectoescritura de manera más rápida y eficaz en cuanto a ortografía, legibilidad y presentación (e. g. Kollberg, Cederlund \& Severinson-Eklundh apud Cassany, 2003b), pero que difícilmente atienden cuestiones estratégicas más globales como el análisis del lector o las formas discursivas. Cassany subraya que enseñar a escribir hoy en día dista mucho de cuando no existían las computadoras, ya que la escritura electrónica ha modificado tanto las prácticas sociales de comunicación como sus formas de enseñanza y de aprendizaje.

En el campo de la lectura, Rodríguez-Illera (2003) retoma ideas de otros autores para plantear la distinción entre "leer de la pantalla" y "leer con la pantalla". El autor refiere que así como Salomon, Perkins y Globerson (1992) diferencian que aprender de la tecnología significa que las computadoras son utilizadas como tutores, en tanto que aprender con la tecnología supone aprender mientras se hace uso de ella como una herramienta que extiende nuestras capacidades, esta idea trasladada al campo de la lectura electrónica con fines educativos lleva al autor a considerar que el medio tecnológico proporciona "facilidades posibilitadoras" (affordances). Al leer con pantallas, las aplicaciones del software posibilitan determinadas acciones y no otras, permitiendo así la extensión y distribución de nuestras prácticas de lectura, en el sentido de cognición distribuida de Salomon (1993b). Asimismo, otras facilidades adicionales que respondan a estrategias docentes o lectoras pueden ofrecer gran utilidad al presentarse en la forma habitual de ayudas que dan soporte o andamiaje, por ejemplo, añadiendo comentarios a partes difíciles de interpretar, permitiendo el enlace a un diccionario, creando una reflexión sobre lo que se lee, diseñando una hipertextualidad entre varios textos, entre otras. La inclusión de estas facilidades en textos 
electrónicos ha sido un campo de intervención educativa interesante que ha emergido hacia finales de la década pasada (e. g. Matthew, 1996; McKenna, 1998).

Si bien el uso de las TIC posibilita, entre otras cosas, la flexibilidad en la escritura, copiar textos, compararlos, eliminar partes del mismo, ligar una palabra escrita con faltas de ortografía con un conjunto de sugerencias alternativas de cómo escribirla sin errores, y tener una inmediata respuesta a las operaciones que hacemos, todo con el toque de unos cuantos botones. ¿Se puede afirmar qué con el uso de las computadoras estamos arribando a una revolución en la escritura/lectura? ¿Lo que hacemos con la computadora no tiene nada que ver con lo que hacemos con el papel y lápiz? ¿Nuestras formas de interpretación y producción de textos digitales son completamente distintas a las formas de interpretación y producción de textos impresos?

Con la finalidad de explorar empíricamente estas preguntas, se presenta un estudio de corte cualitativo en el cual se analizan las prácticas de lengua escrita que despliegan ocho díadas de estudiantes al realizar diversas tareas escolares utilizando la computadora. Se busca ilustrar, por un lado, las múltiples formas en que las prácticas con textos impresos conviven con las de textos digitales y, por otro, la multiplicidad de prácticas $y$ formas textuales que intervienen en una actividad concreta. Este análisis conforma parte de una investigación más amplia donde se busca estudiar las formas de participación de estudiantes de bachillerato en situaciones de aprendizaje con la tecnología. Por razones de espacio, sólo se hará referencia a aquellos aspectos de este trabajo necesarios para presentar este análisis.

\section{El proyecto de investigación}

David: ¿Qué pasó?

Israel: Creo que faltó algo. A ver, a ver. (Regresa a la pantalla con el codigo fuente y lo revisa con detenimiento).

Israel: El Body y el HTML. Mmmm. No, está mal éste. (Revisa los codigos y borra espacios de más que hay enseguida del signo "<” en dos de las líneas de instrucción).
David: Porque está igual con el del pizarrón (Justificándose).

(Israel salva el codigo y pasa a la presentación de la página web, la actualiza. Anteriormente había salido solo un fondo en blanco con códigos anotados y ahora ya se aprecia la presentación con color, formas y textos).

David: ¿Qué le pasó?

Israel: Es que lo, le habías puesto el espacio.

David: Ay, por un espacio.

Israel: ¡Sí por ese espacio!

David: Ándale (incrédulo).

Este fragmento de la interacción que tienen los alumnos David e Israel mientras codifican y revisan un ejercicio para su presentación en formato HTML ilustra cómo uno de los jóvenes reconoce en un lenguaje de programación un error inadvertido por su compañero, lo cual provoca fallas en una presentación de página Web. Con la finalidad de ahondar en el conocimiento de las formas de leer y escribir que los alumnos utilizan al trabajar conjuntamente en actividades escolares empleando la computadora, se realizó este estudio entre alumnos mexicanos de bachillerato del sistema de enseñanza media superior tecnológica. Como parte de esta investigación, surgieron dos preguntas: ¿Cuáles son las prácticas de lectura y escritura que despliegan los alumnos al aprender a usar la computadora en la escuela? y ¿Cuáles de esas prácticas son propias o no de los entornos computacionales?

Para dar respuesta a estas preguntas, a continuación se describe brevemente el escenario, los participantes en la investigación, el tipo de datos recogidos y las formas de recopilación, así como las pautas analíticas desarrolladas. En secciones posteriores se presentan los hallazgos, discusión y conclusiones.

\section{Escenario, participantes y recopilación de datos}

La investigación se realizó en el Centro de Estudios Tecnológicos, Industrial y de Servicios (CETIS \# 154), ubicado en un poblado con un nivel socioeconómico medio-bajo, hacia las afueras en el sur de 
la Ciudad de México, llamado San Pedro Mártir. Se trata de un plantel de enseñanza pública en el que se imparten estudios de bachillerato tecnológico, que en México forma parte del siguiente nivel educativo al concluir la enseñanza básica, y que es previo a los estudios profesionales. Los alumnos del CETIS \# 154 egresan con alguna de las siguientes cinco carreras técnicas: administración, análisis y tecnología de alimentos, computación, mantenimiento, y máquinas de combustión interna. Las materias que se cursan son prácticamente las mismas que se ofrecen en el tronco común de cualquier institución de enseñanza media superior: ciencias sociales, biología, química, filosofía y matemáticas, principalmente. Al término de los estudios, que tienen una duración de tres años repartidos en seis semestres en cada una de las especialidades que se imparten, se otorga un certificado de bachillerato, cédula profesional y título, una vez cubiertos los requisitos establecidos.

El plantel cuenta con áreas administrativas que se encuentran equipadas con computadoras, cuyo uso principal es el de elaborar documentos oficiales y administrativos con el uso de programas o softwares comerciales, tales como procesadores de texto y hojas de cálculo, principalmente. Los alumnos tienen acceso a las computadoras en el laboratorio de cómputo, en un anexo a este laboratorio y en el laboratorio de física. Todas las prácticas de computación, tanto del tronco común como de la carrera de computación, se imparten en el laboratorio de cómputo, lugar donde se decidió centrar el trabajo de campo, debido a que ahí las computadoras están destinadas exclusivamente al uso de los alumnos. En este lugar se les permite utilizar los equipos en dos tipos de situaciones: para realizar actividades dirigidas (las prácticas de computación conducidas por un profesor o profesora), y para realizar otras actividades académicas en forma independiente (generalmente tareas escolares).

El laboratorio de cómputo está conformado por tres áreas de trabajo (Figura 1). Las dos áreas a ambos extremos se utilizan como aulas para impartir cursos, y cuenta cada una con un acceso del exterior (secciones 1 y 3, Figura 1), en tanto que la sección intermedia es un espacio para los profesores (sección 2, Figura 1) que se encuentra intercomunicada con las dos aulas.

Figura 1 - Croquis del Laboratorio de Cómputo

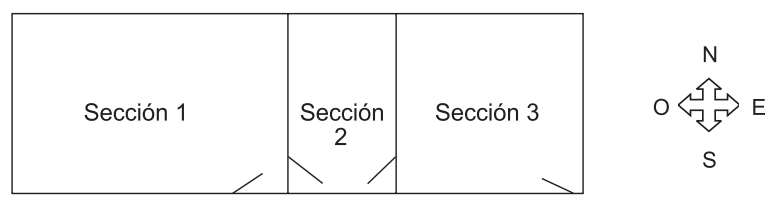

Sobre las mesas ordenadas en filas se ubican de 16 a 20 equipos de cómputo (CPU+pantalla+teclado+ratón). En una de las aulas (sección 1) los equipos son más modernos (Pentium III), en tanto que los de la otra son de una versión anterior. A todas las computadoras se les ha instalado los programas básicos de Windows y de Microsoft Office, así como paquetería más especializada que se va agregando, conforme la requieren los maestros con sus alumnos en clase. Cabe señalar que los equipos están en red y el servidor está controlado por el profesor encargado del laboratorio; asimismo, cuentan con acceso a Internet.

Participaron 16 estudiantes voluntariamente, organizados en ocho díadas (cinco de alumnas y tres de alumnos), con edades entre 15 y 18 años, conforme se desglosa en la Tabla 1.

Tabla 1 - Participantes en el estudio

\begin{tabular}{|l|c|c|c|c|}
\hline \multirow{2}{*}{ ALUMNOS } & \multicolumn{3}{|c|}{ SEMESTRE } & \multirow{2}{*}{ TOTAL } \\
\cline { 2 - 4 } & $2^{\circ}$ & $4^{\circ}$ & $6^{\circ}$ & \\
\hline Mujeres & 2 & 4 & 4 & 10 \\
\hline Hombres & 2 & 0 & 4 & 6 \\
\hline Total & 4 & 4 & 8 & 16 \\
\hline
\end{tabular}

Este estudio se sitúa en la perspectiva sociocultural que destaca el aspecto comunicativo del lenguaje escrito como una herramienta cultural que comprende múltiples presentaciones, formas, géneros, propósitos y prácticas. Considerando el interés tanto en el análisis de los aspectos sociales como de las situaciones específicas, que enmarcan y dan sentido a dichas 
prácticas, la recopilación de datos se realizó mediante las siguientes actividades:

a) notas de campo;

b) entrevistas a maestros sobre sus concepciones alrededor de la lectura y la escritura;

c) observaciones de estudiantes participando en "eventos de lengua escrita" (se explica este término más adelante) en el contexto escolar (también se recopilaron algunos productos escritos como son: trabajos en computadora, hojas de cuaderno, notas etc.).

En el Cuadro 1 se describe cómo quedó conformado el corpus empírico.

Un primer acercamiento al campo consistió en conversaciones con personal del plantel, con los profesores de las asignaturas que se imparten en el

Cuadro 1 - Corpus empírico

\begin{tabular}{|l|l|c|c|}
\hline \multicolumn{1}{|c|}{ DATOS } & \multicolumn{1}{|c|}{ DESCRIPCIÓN } & NUM. & TIEMPO \\
\hline Notas de campo & $\begin{array}{l}\text { Se recupera por escrito, tanto información sobre alumnos al trabajar en las } \\
\text { computadoras como aspectos del contexto escolar. }\end{array}$ & 22 & $7 \mathrm{~h}$ \\
\hline $\begin{array}{l}\text { Audiograbaciones de } \\
\text { entrevistas a maestros }\end{array}$ & $\begin{array}{l}\text { Se exploran las opiniones y argumentos de algunos maestros acerca del uso } \\
\text { de las TIC en el ámbito educativo, a partir de la experiencia con sus alumnos. }\end{array}$ & 3 & $6 \mathrm{~h}$ \\
\hline $\begin{array}{l}\text { Videograbaciones de } \\
\text { alumnos }\end{array}$ & $\begin{array}{l}\text { Se capta a díadas de alumnos utilizando la computadora en situaciones } \\
\text { tanto dirigidas (tomando clases) como independientes (haciendo tareas } \\
\text { por su cuenta). Se aprecian las interacciones discursivas de los participan- } \\
\text { tes y sus acciones en la computadora, para identificar prácticas de lengua } \\
\text { escrita y formas de participación social entre ellos. }\end{array}$ & 8 & $10 \mathrm{~h} 43 \mathrm{~min}$. \\
\hline & TOTAL & 33 & $23 \mathrm{~h} 43 \mathrm{~min}$. \\
\hline
\end{tabular}

laboratorio de cómputo, y otros cuyas clases se imparten fuera del mismo. También se realizaron observaciones y registros de lo que ocurría en el laboratorio y fuera de él. Lo anterior tuvo la finalidad de tener un panorama general del uso que se hace de las computadoras y la forma en que interactúan los jóvenes alumnos alrededor de ellas, así como el tipo de demandas que esta acción les impone.

A partir del primer acercamiento se identificaron tres situaciones básicas de uso de las computadoras por parte de los alumnos, en las cuales se organizó el levantamiento de datos correspondiente. Estas situaciones son:

\section{$1^{\text {a }}$ Tomando clases en el laboratorio de cómputo}

Todos los alumnos del plantel participan en los cursos de introducción al uso de las computadoras, independientemente de la carrera que cursen. Acuden al laboratorio en un horario que varía conforme a los ajustes que decida realizar su maestro o maestra.

\section{$2^{\text {a }}$ Uso de las computadoras en el "horario libre"}

En los horarios en los que el laboratorio de cómputo no se encuentra utilizado para alguna clase, se asigna el denominado horario libre: espacios intermedios entre clase y clase que pueden ser aprovechados por los estudiantes para utilizar libremente los equipos; siempre y cuando efectúen actividades exclusivamente académicas y esté presente el encargado, que comúnmente es un profesor asignado en horarios específicos. Aquí los estudiantes, en forma individual o en grupos, tienen acceso a una de las computadoras, previo depósito de su credencial escolar y asignación de equipo. 
El desplazamiento de prácticas impresas y la apropiación de prácticas digitales

\section{$3^{\text {a }}$ Construcción de páginas Web}

La tercera situación en la que se efectuó el levantamiento de datos fue cuanto los alumnos del sexto semestre de la carrera de computación estaban construyendo su página Web, que constituía el trabajo final para la asignatura seminario de sistemas. Para realizar su trabajo, los jóvenes disponían de espacio dentro de su horario de clase y también en horario libre, además de lo que pudieran realizar en su casa.

En las tres situaciones descritas se recabaron registros fílmicos y de audio, mientras los alumnos trabajan conjuntamente utilizando las TIC.

\section{Procedimiento analítico}

El análisis que aquí se presenta se centra exclusivamente en las videograbaciones realizadas a alumnos trabajando en computadoras. Primero se procedió a la transcripción de las interacciones verbales registradas. Posteriormente, considerando que tales interacciones se apoyan fuertemente y de forma permanente en el trabajo que realizan los participantes con la computadora, fue necesaria la inclusión de la descripción de lo que ejecutan en ella; sin la descripción de la imagen hubiera sido incomprensible la transcripción de la sola interacción verbal. Asimismo, ambos aspectos eran necesarios plasmarlos por escrito, considerando la importancia de desplegar lo más amplia y claramente posible lo que los alumnos estaban diciendo y haciendo a la vez.

Dado que se determinó apoyar el análisis utilizando como herramienta el software científico para las ciencias sociales llamado ATLAS/ti (versión 4.2), ${ }^{2}$ las transcripciones y descripciones se realizaron utilizando un procesador de texto, en un formato en el

${ }^{2}$ Cabe aclarar que ATLAS/ti es una herramienta informática cuyo objetivo es, entre otros, facilitar el análisis cualitativo de datos textuales, auxiliando en la labor de segmentación del texto, codificación, organización de comentarios y anotaciones, principalmente. que se despliega cada turno de interacción entre los participantes, respetando cierto tipo de organización y etiquetas para distinguir a cada uno, así como diferenciando las descripciones en texto con mayúsculas.

Con esta preparación de los datos se conformó un conjunto de ocho registros ampliados que fueron analizados y organizados en función de las siguientes dos categorías de análisis, que se consideraron útiles para dar cuenta de la presencia de las prácticas de lengua escrita de la manera más comprensible.

\section{Experiencia en entornos computacionales}

Los alumnos se diferenciaron en básicos o avanzados, en función de experiencia que tenían en el manejo de las computadoras. A partir de los trabajos realizados por Noss y Hoyles (1996), sobre aprendizaje en entornos computacionales, se consideró identificar como básicos a aquellos usuarios que están familiarizados con la computadora y con algunos softwares de empleo universal o generalizado; se concretan a elaborar un trabajo, guardarlo y poderlo recuperar cuando sea necesario. Por su parte, se consideraron como avanzados a aquellos usuarios autónomos, selectivos, críticos y rigurosos de la computadora; que realizan tareas utilizando software especializado, para mostrar su trabajo a los demás; saben entrar a la Internet, dónde buscar información y bajarla; y cuentan con un amplio repertorio de utilización de la computadora. La principal diferencia entre ambas subcategorías es que los avanzados son autónomos e independientes en el uso de las TIC y los básicos no lo son

\section{Forma en la que trabajan}

Se diferenció a los alumnos tomando en cuenta si su trabajo es dirigido o independiente. En la forma de trabajo dirigido se consideró a aquellos alumnos quienes fueron captados en clase, bajo la conducción del maestro o maestra y siguiendo indicaciones puntuales. En trabajo independiente fueron catalogados los estudiantes que realizaban su tarea en condiciones extra-clase, sin la guía o presencia del maestro o maestra. 
Cuadro 2 - Organización de los participantes

\begin{tabular}{|c|c|}
\hline GRUPO & PARTICIPANTES \\
\hline GRUPO 1: Básico-Dirigido & $\begin{array}{l}\text { Estudiantes en semestres iniciales, en la clase de la maestra Juana Ortiz sobre usos } \\
\text { básicos de la computadora. } \\
\text { - YADIRA y JAZMÍN. Cómo insertar tablas y la reproducción de su horario de } \\
\text { clases, utilizando el procesador de textos Word. } \\
\text { - ISMAEL y JULIÁN. Funciones de los botones de la "Barra de Herramientas } \\
\text { Formato", del programa Word. }\end{array}$ \\
\hline GRUPO 2: Básico-Independiente & $\begin{array}{l}\text { Alumnas en semestres intermedios, en el horario libre, haciendo uso elemental de } \\
\text { la computadora, sin mostrar un amplio conocimiento de su funcionamiento. } \\
\text { - ARIZA y GABRIELA. Gráficas en el programa Excel, a partir de los datos de una } \\
\text { encuesta que aplicaron. } \\
\text { - CLAUDIA y MIRIAM. Resumen de un trabajo que ya expusieron a sus } \\
\text { compañeros en clase, utilizando el programa Word. }\end{array}$ \\
\hline GRUPO 3: Avanzado-Dirigido & $\begin{array}{l}\text { Estudiantes en semestres avanzados, en la clase del maestro Delfino Martínez so- } \\
\text { bre uso de un software especializado. } \\
\text { - ÁNGEL y LUIS. Cómo realizar diferentes tipos de animaciones utilizando el } \\
\text { programa Flash. } \\
\text { - DAVID e ISRAEL. Cómo insertar animaciones en una página Web. }\end{array}$ \\
\hline GRUPO 4: Avanzado-Independiente & $\begin{array}{l}\text { Alumnas en semestres avanzados, trabajando en el horario libre, haciendo un uso } \\
\text { complejo de la computadora y de uno o más softwares. } \\
\text { - ESTELA y CARLA. Construyendo página Web sobre el Mundial de Fútbol. } \\
\text { - ÉVELYN y MARIANA. Construyendo página Web sobre el pueblo donde se } \\
\text { ubica su escuela, que es San Pedro Mártir. }\end{array}$ \\
\hline
\end{tabular}

En el Cuadro 2 se presenta la organización de los alumnos participantes, conforme a las diferencias arriba señaladas.

El procedimiento analítico prosiguió considerando cada registro ampliado como un "evento de lengua escrita", mismo que, retomando a autores como Street (1993), Barton (1994), Heath (1983), y Anderson, Teale y Estrada (1980), puede formularse como cualquier oportunidad en la vida diaria que involucra una o más personas, en la que interviene de manera importante la comprensión y/o producción de la letra impresa, incluyendo el habla que se genera alrededor de ella y los procesos interpretativos de los participantes. En este punto del estudio, el análisis consistió en (a) desentrañar el proceso de construcción del evento de lengua escrita, y (b) identificar y analizar las prácticas de lengua escrita que fueron desplegadas por los participantes durante la construcción de cada evento. Para la primera de estas dos aproximaciones analíticas, el interés se centró en comprender qué secuencia de acciones desempeñan los participantes a lo largo de todo el evento y que lo constituyen como un todo. Para la segunda aproximación, se identificaron y analizaron las formas distintas en que se revelan las prácticas de lengua escrita entre los alumnos.

En el siguiente apartado, primero se ilustra con un ejemplo de los procesos analíticos realizados, para luego presentar los hallazgos del estudio.

\section{De lo impreso a lo digital: "Tú haz el horario como si lo estuvieras haciendo en tu cuaderno"}

A continuación se presenta, por cuestiones de espacio, un fragmento de la narrativa de uno de los eventos de lengua escrita, con fines de ilustrar el proceso de análisis efectuado con todos los registros. Se trata de la díada conformada por Yadira y Jazmín, del Grupo 1: Básico-Dirigido, alumnas del $2^{\circ}$ semestre de la carrera de computación, quienes fueron captadas durante una clase introductoria a la computación.

A partir de la narrativa analítica completa se identifican 10 prácticas de lectura y escritura que despliegan las alumnas (Tabla 2), tres de las cuales utilizan con mayor frecuencia a lo largo de su tarea, como se explica a continuación. Cabe aclarar que más adelante se describe en que consiste cada una de éstas. 


\section{YADIRA Y JAZMÍN}

El evento de lengua escrita en el que participan consiste en reproducir un texto organizado en un formato de tabla (horario de clases), siguiendo un modelo impreso (su horario de clases escrito a mano en una tarjetita y una muestra impresa de un horario escolar que la maestra les entregó a manera de guía). Para elaborar el formato, la maestra les solicita utilizar el procesador de textos Word, aplicar la opción de "Insertar Tabla" y diversos procedimientos del menú "Tabla".

Las alumnas comienzan su tarea y enseguida se dan cuenta de su desconocimiento de funciones del teclado, como por ejemplo poner acentos; situación que tratan de solventar sin éxito probando varias teclas, y optan por dejar sin acentuar las palabras. En un punto determinado, las alumnas identifican que deben elaborar un cuadro o tabla, cosa que también desconocen. Finalmente le comentan a la maestra que ellas no asistieron a la clase anterior, con lo que la profesora Juana determina sentarse con las alumnas a demostrarles cómo se elabora una tabla. Para ello, manipula el teclado y el ratón, al tiempo que va explicando el procedimiento paso por paso. Utiliza un modelo impreso, que es el horario de las clases de las alumnas. Demuestra el llenado de celdas, cómo modificar el ancho de columna y el tamaño de las letras, así como combinar celdas. Al final, cierra la aplicación sin guardar los cambios y la abre de nuevo dejando la pantalla en blanco para que las alumnas empiecen su tarea.

Ellas insertan una tabla con el número correspondiente de filas y columnas basándose en su horario de clases. Yadira es quien manipula el teclado, va llenando los encabezados de las columnas y modificando el tamaño de las letras al llenar cada celda. Jazmín dicta a su compañera lo que va en cada celda (horario y asignatura). A lo largo del proceso van descubriendo funciones del software como el autoajuste del ancho de la columna al texto y la mayúscula inicial automática. Al ir llenando la tabla, ésta se va alargando hacia abajo provocando que en la pantalla a la vista se vean menos renglones, ya que el último se pasa automáticamente a la siguiente página y ellas no se dan cuenta de esto. Piensan que se "recortó" su tabla y buscan a la profesora para que les resuelva este problema, pero como está ocupada con otros alumnos y deben esperar su turno, deciden cerrar la aplicación y volver a empezar de nuevo con la finalidad de insertar otra vez la tabla, esta vez con el número corregido de renglones. Por situaciones similares incluso llegan a iniciar su tabla hasta en tres ocasiones.

Al revisar su trabajo, consideran que el alto de las filas es irregular ya que hay algunos renglones angostos y otros más anchos; lo que quieren es que estén uniformes. Ambas sugieren algunas maneras de arreglar esto y prueban cada una sin éxito (ensayo y error). Reflexionan y buscan posibles explicaciones de porqué no funcionan sus intentos. En esta etapa las alumnas revisan todo el trabajo y van detectando errores que corrigen. También opinan sobre la presentación y hacen ajustes de formateo tratando de igualar el modelo impreso (centrado manual, mayúscula inicial, ancho de renglones).

Dan por terminada la tarea, y deciden esperar a la maestra para que la revise. La espera se prolonga por varios minutos hasta que por fin llega su turno de revisión. La maestra en cuestión de segundos observa el trabajo, las felicita, les explica y demuestra como centrar el texto usando el menú "Formato". Le dice al grupo que ya se puede retirar. Yadira y Jazmín ya no le exponen sus dudas, guardan sus cosas y se retiran.

Tabla 2 - Prácticas de lectura y escritura que despliegan Yadira y Jazmín

\begin{tabular}{|r|c|}
\hline \multicolumn{1}{|c|}{ Lectura/Escritura } & frecuencia \\
\hline 1. Escribir & 16 \\
2. Dictar-escribir texto & 13 \\
3. Formatear texto & 10 \\
4. Corregir & 9 \\
5. Revisión-planeación & 9 \\
6. Leer para revisar & 8 \\
7. Reflexión & 6 \\
8. Ortografía & 4 \\
9. Negociar texto & 3 \\
10. Copiar & 2 \\
\hline Totales & 80 \\
\hline
\end{tabular}

El análisis revela que el evento de lengua escrita en el que participan las alumnas demanda la reproducción de un texto organizado en un formato de tabla, siguiendo un modelo impreso que tratan de imitar en forma digital. Para elaborar el horario de clases solicitado por la maestra, utilizan el procesador de textos Word y aplican varios procedimientos del menú "Tabla". Las prácticas de lengua escrita mostradas por estas alumnas consisten fundamentalmente en escribir en pantalla a partir del dictado, una a la otra, del contenido a anotar en su tabla; ocasionalmente recurren al copiado directamente de los modelos impresos que tienen.

Es interesante dar cuenta como al no recordar las alumnas el procedimiento que les demostró la maestra para combinar dos celdas en una, cuando tratan de anotar una misma asignatura que cursan en 
dos horas de clase, Jazmín hace el siguiente comentario a su compañera:

Jazmín: Ahora nada más una hora de Taller, o sea, nada más como aquí (señalando en su libreta). Y ya abajo le vamos a poner igual. Y ya después veremos la manera de unirlos (en una misma celda). Ira tú haz el horario como si lo estuvieras haciendo en tu cuaderno. Como está aquí (señalando su horario en manuscrito). ¿Ya?

(Ref: 7-2CV4-1- CC-07.06.02, p. 24)

Este extracto ejemplifica la perspectiva que tienen las alumnas de que la pantalla de la computadora es un símil de una hoja del cuaderno y el programa es un medio para reproducir un manuscrito, en un formato bien organizado en columnas y filas uniformemente distribuidas.

En otro momento, creen que se les "recortó" un renglón de la tabla, como se ilustra en este fragmento de su interacción.

Yadira: Pero ve. (Al escribir en dos renglones el nombre de la asignatura "actividades cocurriculares", la tabla se hace mas larga pasando la decima fila a la pagina siguiente, quedando a la vista la tabla solo con nueve filas).

Jazmín: ¿Qué haces?

Yadira: Nada.

Jazmín: ¿Qué hiciste? A ver, cuántos tienen que ser.

Yadira: De ahí para abajo, 10. (Con el indice derecho cuenta sobre la pantalla las filas de la tabla). Uno, dos, tres, cuatro, cinco, seis, siete, ocho. ¡Ay guey! (Riéndose).

Jazmín: (También se ríe). ¿No nos recortó esto ahorita?

(Ref: 7-2CV4-1- CC-07.06.02, p. 13)

Lo anterior parece también indicar que perciben la pantalla como si físicamente fuera una hoja de papel, como si lo que han escrito en su pantalla no pudiera moverse de ahí por sí solo, tal como ocurre en una hoja del cuaderno. Es por ello que se asombran, por no comprender cómo algo que han escrito en la misma hoja/pantalla pueda pasarse a otra hoja/ pantalla, y creen que se recortó su horario de clases, el cual vuelven a comenzar su realización hasta en tres ocasiones por suposiciones similares.

A lo largo de la construcción de este evento de lengua escrita destaca como Yadira y Jazmín van haciendo pausas para revisar su trabajo y reflexionar sobre su realización, lo cual implica estar leyendo de la pantalla y opinar si el trabajo imita adecuadamente al modelo a copiar, ya que para ellas lo importante es reproducir su horario de clases lo más semejante a la muestra que les proporcionó la maestra, de manera que no se detienen a explorar y conocer más sobre el funcionamiento del programa Word y sus posibilidades, sino que priorizan el hacer bien su horario en la pantalla de la computadora. Inclusive, en otro momento de la interacción, llegan a levantar la muestra en papel y colocarla sobre su pantalla, para compararla contra el formato digital que hicieron, viendo a través de la transparencia de la hoja a contraluz de la pantalla, y verificando si están iguales las filas y columnas. Lo anterior se ilustra en el fragmento que sigue.

Jazmín: Está casi del mismo tamaño, ¿no?, nomás es, están.

Yadira: No, no. Ve, ve.

(Las alumnas han colocado la hoja muestra sobre la pantalla y sobreponiendo el formato con el que ellas realizaron y comparandolo a contraluz).

(Ref: 7-2CV4-1- CC-07.06.02, p. 50)

También detectan errores que buscan corregir, demostrando poco dominio del programa en uso, así como de la manipulación del teclado y ratón. Por ejemplo, usan las flechas del teclado en lugar del ratón para ubicar el cursor en determinada celda, cambian el formato por celda en lugar de hacerlo por filas o columnas, no controlan el movimiento del ratón al seleccionar una o más celdas, centran un texto manualmente con la barra espaciadora, entre otros. Particularmente se preocupan de la presentación y formateo, más que por su contenido u ortografía, es decir, tratan de que el número de renglones y columnas sea el correcto, que el ancho y alto de las mismas esté 
Cuadro 3 - Análisis de las prácticas de lengua escrita desplegadas por cada díada de acuerdo a la producción que realizan

\begin{tabular}{|c|c|c|c|c|c|c|c|c|}
\hline DÍADAS & $\begin{array}{l}\text { ISMAEL Y } \\
\text { JULIÁN }\end{array}$ & $\begin{array}{l}\text { YADIRA Y } \\
\text { JAZMÍN }\end{array}$ & $\begin{array}{l}\text { CLAUDIA Y } \\
\text { MIRIAM }\end{array}$ & $\begin{array}{l}\text { ARIZAY } \\
\text { GABRIELA }\end{array}$ & $\begin{array}{l}\text { ÁNGEL Y } \\
\text { LUIS }\end{array}$ & $\begin{array}{l}\text { DAVID E } \\
\text { ISRAEL }\end{array}$ & $\begin{array}{l}\text { ESTELAY } \\
\text { CARLA }\end{array}$ & $\begin{array}{l}\text { ÉVELYN Y } \\
\text { MARIANA }\end{array}$ \\
\hline $\begin{array}{l}\text { EXPERIENCIA- } \\
\text { TRABAJO }\end{array}$ & \multicolumn{2}{|c|}{ BÁSICO-DIRIGIDO } & \multicolumn{2}{|c|}{ BÁSICO-INDEPENDIENTE } & \multicolumn{2}{|c|}{ AVANZADO-DIRIGIDO } & \multicolumn{2}{|c|}{$\begin{array}{l}\text { AVANZADO- } \\
\text { INDEPENDIENTE }\end{array}$} \\
\hline PRODUCCIÓN & $\begin{array}{l}\text { Reporte de la } \\
\text { práctica } \\
\text { escolar }\end{array}$ & $\begin{array}{l}\text { Reproducción } \\
\text { del horario de } \\
\text { clases }\end{array}$ & $\begin{array}{l}\text { Resumen del } \\
\text { libro para } \\
\text { entregar }\end{array}$ & $\begin{array}{l}\text { Gráficas para } \\
\text { ilustrar un } \\
\text { trabajo } \\
\text { escolar }\end{array}$ & $\begin{array}{l}\text { Animaciones } \\
\text { con tres } \\
\text { distintos } \\
\text { procedimientos }\end{array}$ & $\begin{array}{l}\text { Animaciones } \\
\text { dentro de } \\
\text { una Página } \\
\text { Web }\end{array}$ & $\begin{array}{l}\text { Página Web } \\
\text { sobre fútbol }\end{array}$ & $\begin{array}{l}\text { Página Web } \\
\text { sobre el } \\
\text { pueblo San } \\
\text { Pedro Mártir }\end{array}$ \\
\hline $\begin{array}{l}\text { PRÁCTICAS } \\
\text { DE LENGUA } \\
\text { ESCRITA }\end{array}$ & $\begin{array}{l}\text { - Tomar } \\
\text { dictado de la } \\
\text { maestra, en } \\
\text { el cuaderno. } \\
\text { - Escribir en } \\
\text { pantalla } \\
\text { palabras, uno } \\
\text { o dos } \\
\text { párrafos. } \\
\text { - Corregir lo } \\
\text { escrito y } \\
\text { formatearlo, } \\
\text { para } \\
\text { comprobar } \\
\text { las funciones } \\
\text { de la "Barra } \\
\text { de } \\
\text { Herramientas } \\
\text { Formato } \\
\text { (BHF). } \\
\text { - Leer en } \\
\text { pantalla } \\
\text { buscando } \\
\text { información } \\
\text { específica de } \\
\text { las leyendas } \\
\text { en los } \\
\text { botones de la } \\
\text { BHF. } \\
\text { - Construir } \\
\text { un texto en el } \\
\text { cuaderno } \\
\text { (reporte de la } \\
\text { práctica). } \\
\text { - Reflexionar } \\
\text { y negociar lo } \\
\text { que se } \\
\text { escribe en el } \\
\text { cuaderno. } \\
\text { - Hacer uso } \\
\text { de la } \\
\text { herramienta } \\
\text { "Sinónimos" } \\
\text { de la } \\
\text { computadora, } \\
\text { como un } \\
\text { auxiliar al } \\
\text { escribir en el } \\
\text { cuaderno. }\end{array}$ & $\begin{array}{l}\text { - Escribir en } \\
\text { pantalla } \\
\text { palabras o } \\
\text { frases cortas, } \\
\text { así como } \\
\text { cifras } \\
\text { numéricas, } \\
\text { que una de } \\
\text { las alumnas } \\
\text { dicta. } \\
\text { - Corregir } \\
\text { escritura y } \\
\text { ortografía, así } \\
\text { como } \\
\text { formatear } \\
\text { texto. } \\
\text { - Leer en } \\
\text { pantalla lo } \\
\text { escrito para } \\
\text { revisar } \\
\text { escritura y } \\
\text { errores de } \\
\text { ortografía. } \\
\text { - Apoyar el } \\
\text { trabajo en } \\
\text { otro texto } \\
\text { escrito } \\
\text { (horario de } \\
\text { clases en } \\
\text { manuscrito) y } \\
\text { guiándose por } \\
\text { una muestra } \\
\text { impresa } \\
\text { proporcionada } \\
\text { por la } \\
\text { maestra. }\end{array}$ & $\begin{array}{l}\text { - Escribir en } \\
\text { pantalla un } \\
\text { texto } \\
\text { organizado en } \\
\text { ideas con } \\
\text { viñetas. } \\
\text { - Dictar lo que } \\
\text { se va } \\
\text { parafraseando, } \\
\text { o eligiendo } \\
\text { fragmentos de } \\
\text { un texto } \\
\text { impreso } \\
\text { (capitulo de } \\
\text { libro) que se } \\
\text { va leyendo en } \\
\text { silencio. } \\
\text { - Escribir en } \\
\text { pantalla con el } \\
\text { apoyo de las } \\
\text { funciones de } \\
\text { formateo y } \\
\text { revisión de } \\
\text { ortografía de la } \\
\text { computadora. } \\
\text { - Leer en } \\
\text { pantalla para } \\
\text { revisar el } \\
\text { escrito y } \\
\text { planear cómo } \\
\text { continuar el } \\
\text { trabajo. }\end{array}$ & $\begin{array}{l}\text { - Escribir en } \\
\text { pantalla } \\
\text { palabras o } \\
\text { frases cortas, } \\
\text { así como } \\
\text { cifras } \\
\text { numéricas. } \\
\text { - Dictar la } \\
\text { información } \\
\text { que la otra } \\
\text { alumna } \\
\text { escribe. } \\
\text { - Leer en } \\
\text { pantalla para } \\
\text { seleccionar } \\
\text { de entre las } \\
\text { opciones que } \\
\text { se presentan } \\
\text { en cuadros } \\
\text { de diálogo, lo } \\
\text { cual lleva a } \\
\text { transformar } \\
\text { datos en } \\
\text { gráficas por } \\
\text { medio de un } \\
\text { procedimiento } \\
\text { en la } \\
\text { computadora. }\end{array}$ & $\begin{array}{l}\text { - Leer en } \\
\text { pantalla para } \\
\text { hacer } \\
\text { elecciones de } \\
\text { entre menús y } \\
\text { submenús, así } \\
\text { como de entre } \\
\text { opciones } \\
\text { desplegadas } \\
\text { en cuadros de } \\
\text { diálogo. Lo } \\
\text { que lleva a } \\
\text { crear efectos } \\
\text { de formas y } \\
\text { texto en } \\
\text { movimiento } \\
\text { con tamaños y } \\
\text { colores } \\
\text { diversos. } \\
\text { - Escribir en } \\
\text { pantalla } \\
\text { algunos datos } \\
\text { numéricos en } \\
\text { ventanas } \\
\text { desplegadas } \\
\text { en la pantalla. }\end{array}$ & $\begin{array}{l}\text { - Leer en } \\
\text { pantalla } \\
\text { buscando } \\
\text { opciones } \\
\text { específicas } \\
\text { desplegadas } \\
\text { en menús, } \\
\text { submenús y } \\
\text { cuadros de } \\
\text { diálogo. } \\
\text { Esto se } \\
\text { transforma } \\
\text { en un efecto } \\
\text { dentro de } \\
\text { una } \\
\text { presentación } \\
\text { de página } \\
\text { Web. } \\
\text { - Escribir en } \\
\text { pantalla, } \\
\text { borrar, } \\
\text { cortar-pegar } \\
\text { expresiones } \\
\text { alfabéticas y } \\
\text { numéricas } \\
\text { cifradas en } \\
\text { códigos. }\end{array}$ & $\begin{array}{l}\text { - Negociar y } \\
\text { escribir en } \\
\text { pantalla (en } \\
\text { ocasiones } \\
\text { por dictado), } \\
\text { corregir, } \\
\text { borrar, cortar } \\
\text { y pegar } \\
\text { expresiones } \\
\text { alfabéticas y } \\
\text { numéricas } \\
\text { cifradas en } \\
\text { códigos. } \\
\text { Todo esto se } \\
\text { traduce en } \\
\text { una } \\
\text { presentación } \\
\text { en formato } \\
\text { HTML } \\
\text { multimedia } \\
\text { creado por } \\
\text { ellas. } \\
\text { - Escribir en } \\
\text { pantalla } \\
\text { texto que se } \\
\text { negocia, a } \\
\text { partir de } \\
\text { información } \\
\text { de Internet y } \\
\text { conocimiento } \\
\text { del tema } \\
\text { elegido. } \\
\text { - Leer en } \\
\text { pantalla } \\
\text { buscando } \\
\text { errores en la } \\
\text { sintaxis de } \\
\text { los códigos o } \\
\text { en la } \\
\text { escritura de } \\
\text { los textos. }\end{array}$ & $\begin{array}{l}\text { - Construir } \\
\text { texto y } \\
\text { reflexionar } \\
\text { acerca de lo } \\
\text { que se } \\
\text { escribe del } \\
\text { tema } \\
\text { elegido. } \\
\text { - Negociar y } \\
\text { escribir en } \\
\text { pantalla (en } \\
\text { ocasiones } \\
\text { por dictado), } \\
\text { corregir, } \\
\text { borrar, } \\
\text { cortar y } \\
\text { pegar } \\
\text { expresiones } \\
\text { alfabéticas y } \\
\text { numéricas } \\
\text { cifradas en } \\
\text { códigos. } \\
\text { Esto queda } \\
\text { expresado } \\
\text { en un } \\
\text { formato } \\
\text { HTML } \\
\text { multimedia, } \\
\text { creado por } \\
\text { ellas. } \\
\text { - Leer en } \\
\text { pantalla } \\
\text { para revisar, } \\
\text { tanto el } \\
\text { contenido de } \\
\text { la } \\
\text { presentación } \\
\text { de la página } \\
\text { Web como } \\
\text { su } \\
\text { codificación. }\end{array}$ \\
\hline
\end{tabular}


uniforme y el tamaño de letras adecuado. Por el contrario, pocas ocasiones requieren negociar el texto a escribir o construirlo conjuntamente, ya que solo tratan de seguir un modelo de texto ya elaborado.

Se siguió este mismo procedimiento con todos los eventos de lengua escrita registrados. En el Cuadro 3 se presenta de manera muy sintética una descripción de este análisis, resaltando que cada díada tiene una actividad distinta que realizar, dando lugar a diferentes producciones (tercer renglón del cuadro).

En el Cuadro 3 se han desplegado las díadas organizadas desde aquellas que tienen menor experiencia en entornos computacionales (extremo izquierdo) y que dependen de una guía al realizar su trabajo, hasta las más independientes y expertas (extremo derecho). Bajo esta organización, es posible reconocer los cambios que van ocurriendo en las prácticas de lengua escrita que van desarrollando los participantes, desde la primera díada hasta la última.

- Ismael y Julián hacen un uso de la lengua escrita que es más cercano a las prácticas que utilizan tecnologías anteriores y, por lo tanto, muy ligado a la letra impresa. Es por ello que parte importante de la clase escribe en el cuaderno lo que la maestra dicta y, posteriormente, elabora a mano su reporte de prácticas en la libreta.

- Luego, tanto el horario de clases que realizan Yadira y Jazmín como el resumen de Claudia y Miriam se asemejan más a una transcripción que realizan teniendo ante ellas modelos impresos (tarjeta con el horario manuscrito y libro).

- Después, en Ariza y Gabriela ya se comienza a apreciar una transformación que se realiza en la computadora, al traducir frases y números en representaciones gráficas ya digitalizadas, que pueden imprimirse tal cual, o integrarse a un documento escrito que les dé contexto.

- Continuando con los alumnos con mayor experiencia, esto es, a partir de Ángel y Luis, los resultados que producen no se pretende imprimirlos sino que son animaciones creadas para su presentación digitalizada.

- Asimismo, las prácticas de lengua escrita entre los más experimentados se van alejando de aquellos usos similares al lápiz y papel, es decir, se aprecia que la escritura/lectura de texto no se basa en la revisión del tipo de letra y ortografía, o reproducción de un modelo impreso, como ocurre en las anteriores díadas. En cambio, se introduce, a partir de David e Israel, la escritura de códigos, el uso de funciones de cortar-pegar, y la lectura selectiva fundamentalmente para hacer elecciones a partir de desplegados de menús, submenús y cuadros de diálogo, requeridos para insertar animaciones en su página Web.

- Por último, Estela y Carla, al igual que Évelyn y Mariana, tienen la peculiaridad de recurrir a la construcción conjunta de texto original al conformar su página Web sobre un tema de su interés. Para ello, reflexionan qué escribir y cómo escribirlo para que sea comprensible para un lector que suponen existente. Además, lo que principalmente escriben son códigos, muchos de los cuales negocian entre sí para dar forma a la presentación de su página, conforme van construyendo una idea común acerca de la misma. Por otra parte, leen con fines de detectar errores, principalmente en la codificación de su presentación.

El análisis revela que las prácticas de lengua escrita se van modificando conforme a dos factores principales: la producción a realizar y la fluidez tecnológica. La producción que realizan los alumnos requieren acciones específicas, donde poca influencia parece tener la presencia del maestro o maestra y conforme los alumnos van demostrando mayor fluidez y conocimiento en el manejo del software y haciendo un uso más sofisticado del mismo, van participando en las actividades computacionales de forma más independiente. En esta transformación, es 
El desplazamiento de prácticas impresas y la apropiación de prácticas digitales

posible apreciar cómo las prácticas de lengua escrita se van alejando de un referente impreso, para dar lugar cada vez con mayor presencia a un referente digitalizado, como se explica a continuación.

En términos generales, entre los alumnos básicos las prácticas tienden a ser más similares a las utilizadas con tecnologías anteriores (como papel y lápiz o máquina de escribir). Son participantes que apoyan su actividad fuertemente en impresos como el libro o el cuaderno; por ejemplo, Claudia y Miriam hacen un resumen de un capítulo de su libro de ciencias sociales. También en este grupo se encuentran los únicos que toman dictado de la maestra en su libreta, que son Ismael y Julián, quienes además pasan largo tiempo construyendo juntos el reporte de la práctica escolar del día, que por cierto escriben en su libreta y no en la pantalla. Así, los básicos tienden a seguir modelos impresos y recurrir frecuentemente a la escritura por dictado, limitando el uso de la computadora principalmente a transcripciones. Sin embargo, cuando los alumnos menos expertos participan en actividades de forma más autónoma, en este caso, al trabajar sin guía del maestro o maestra, comienzan a utilizar la computadora como una herramienta que les facilita lo que pueden hacer también con lápiz y papel; claro ejemplo es el caso de Ariza y Gabriela, quienes suministran información en números y frases a la computadora para que ésta, con un asistente del programa Excel, los transforme rápidamente en gráficas con títulos y leyendas que pueden ser insertadas en un trabajo escolar. En este sentido, la utilización de la computadora comienza a ir más allá de la mera transcripción e impresión, para pasar a hacer una transformación digitalizada.

En síntesis, estas cuatro díadas de alumnos con experiencia básica en entornos computacionales principalmente escriben palabras, frases o textos mediante el dictado, a partir de una fuente impresa, ya sea un libro, notas o libreta. Cuando leen, lo hacen principalmente para revisar que el trabajo quede sin errores de escritura o de ortografía. Algunos ya hacen un mayor uso de funciones de la computadora que les facilitan el trabajo, como son las correspondientes a dar formato al texto, revisar ortografía y gramática, así como ayudarse del asistente para la elaboración de gráficos.

En contraste con los básicos, los alumnos más experimentados recurren menos a la escritura o uso del teclado, ya que principalmente llevan a cabo una lectura-selección de entre las opciones que despliegan de menús y submenús, utilizando el clic del ratón. Sus acciones dan resultados básicamente digitalizados. Por ejemplo, Ángel y Luis, que trabajan en forma dirigida, elaboran animaciones en el programa Flash, desplegando menús y eligiendo de ahí las opciones correspondientes a un procedimiento que el maestro les va explicando. Para verificar si hicieron bien su trabajo, no requieren compararlo con algo impreso, como en el caso de las díadas de básicos, sino lo único que hacen es aplicar la tecla Enter, y de esta manera se ejecuta la animación que han creado en ese momento, la que puede incluir figuras, texto de colores y tamaños variados de letras y formas. En ningún momento elaboran su animación con el propósito de imprimirla, sino de apreciarla en la pantalla.

Las alumnas avanzadas que ya trabajan de manera independiente recurren a la escritura de dos maneras que poco se hacen presentes entre el resto de los participantes. Por una parte, para el contenido de su página Web negocian y construyen conjuntamente el texto que desean comunicar al lector que tienen en mente. Por la otra, frecuentemente recurren a la escritura cifrada y datos en un código fuente, información que se transforma en una presentación exclusivamente digitalizada, multimedia, que incluye texto, fotografías, ligas a archivos con información o sitios de Internet, imágenes, colores y formas. Para validar su trabajo, recurren al propio sistema de la computadora, en este caso, hacen correr su presentación en el formato HTML para corroborar si ahí se reflejan o no los ajustes y contenidos anotados previamente en el código fuente.

De forma sucinta, se aprecia que las prácticas de lengua escrita entre los más avanzados se apegan más a las demandas que impone el medio digitalizado propio de la computadora. Su referente para validar 
el trabajo está en el propio sistema de cómputo, verificando en la pantalla si su trabajo lo están realizando correctamente. Incluso consultan otras fuentes digitalizadas para elaborar su trabajo, revisando el código fuente de otra página Web.

A continuación se listan las diferentes prácticas de lectura y escritura desplegadas por los alumnos en este estudio (Cuadro 4); se incluye una descripción breve y se establece si su expresión tiene orígenes en el texto impreso, si se conserva un uso similar en la computadora, si es el caso de que se transforma su uso de acuerdo con las demandas del nuevo medio, o se trata de formas nuevas que la tecnología impone.

De los distintos usos de lectura y escritura desplegados por los alumnos, el escribir en el cuaderno es el único propio del medio impreso; otros seis tienen su origen también en el medio impreso y se conservan al pasar al texto digital, como copiar y corregir la es-

Cuadro 4 - Origen o transformaciones de las prácticas de lectoescritura

\begin{tabular}{|c|c|c|}
\hline LECTURA/ESCRITURA & DESCRIPCIÓN & $\begin{array}{l}\text { ORIGEN O } \\
\text { TRANSFORMACIÓN }\end{array}$ \\
\hline 1. Escribir en cuaderno & Hacer anotaciones manuscritas en la libreta u hoja suelta. & $\begin{array}{l}\text { Propio del material } \\
\text { impreso/manuscrito. }\end{array}$ \\
\hline 2. Copiar & $\begin{array}{l}\text { Acción de escribir en la pantalla, copiando directamente de otro texto impreso que } \\
\text { puede ser un libro, hojas sueltas, cuaderno, notas manuscritas etc. }\end{array}$ & \multirow{6}{*}{$\begin{array}{l}\text { Tienen su origen en } \\
\text { el material impreso/ } \\
\text { manuscrito y se } \\
\text { conserva al pasar } \\
\text { a un entorno } \\
\text { computacional. }\end{array}$} \\
\hline 3. Dictar-escribir texto & $\begin{array}{l}\text { Se dicta generalmente a partir de un texto impreso que puede ser hojas de } \\
\text { prácticas, libro, cuaderno. Comúnmente, uno de los participantes dicta y el otro } \\
\text { escribe. Muy ocasionalmente el dictado se hace sin tener referente impreso. }\end{array}$ & \\
\hline 4. Leer y comentar & Ir leyendo de la pantalla y comentar acerca de lo que dice. & \\
\hline 5. Negociar texto & $\begin{array}{l}\text { Ponerse de acuerdo en lo que se va a escribir, o en seleccionar la información } \\
\text { escrita que se va a utilizar en un determinado momento (no incluye anotar } \\
\text { códigos). }\end{array}$ & \\
\hline 6. Reflexionar & $\begin{array}{l}\text { Expresar en voz alta si lo que se está haciendo está bien. También incluye reflexionar } \\
\text { sobre la forma en que se está escribiendo o lo que se está queriendo decir con lo } \\
\text { que se escribe. }\end{array}$ & \\
\hline 7. Revisar-planear & $\begin{array}{l}\text { Examinar lo que se está haciendo, lo cual implica leer lo que se ha realizado y/o } \\
\text { compararlo con otros materiales escritos, para corregirlo (escribir) o confirmarlo. } \\
\text { Generalmente se acompaña de planes de cómo seguir adelante en la realización } \\
\text { de la tarea. }\end{array}$ & \\
\hline 8. Dictar-escribir código & $\begin{array}{l}\text { Se dicta información cifrada en códigos de programación específicos que se escriben } \\
\text { dentro del denominado código fuente de una página Web. }\end{array}$ & \multirow{8}{*}{$\begin{array}{l}\text { Tienen su origen en el } \\
\text { material impreso/ } \\
\text { manuscrito pero sufre } \\
\text { transformaciones al } \\
\text { pasar a un entorno } \\
\text { computacional. }\end{array}$} \\
\hline 9. Escribir & $\begin{array}{l}\text { Teclear y que aparezca en la pantalla lo escrito es una actividad recurrente duran- } \\
\text { te todo el trabajo de los alumnos(as). Aquí no se toma en cuenta lo que se escribe } \\
\text { por dictado o copia. }\end{array}$ & \\
\hline 10. Corregir & $\begin{array}{l}\text { Cambiar lo que ya se escribió ya sea porque el propio alumno que escribe se da } \\
\text { cuenta del error o porque el compañero se lo hace notar. }\end{array}$ & \\
\hline 11. Formatear texto & $\begin{array}{l}\text { Dar formato al texto escrito o a la presentación del trabajo, lo cual puede incluir: } \\
\text { centrar, poner negrillas, poner itálicas, organizar en viñetas o lista numerada. Tam- } \\
\text { bién incluye centrar o dar formato a imágenes, recuadros etc., lo cual ocurre } \\
\text { esporádicamente. }\end{array}$ & \\
\hline $\begin{array}{l}\text { 12. Leer para comprender } \\
\text { información }\end{array}$ & $\begin{array}{l}\text { Leer en pantalla con la finalidad de comprender la información desplegada y } \\
\text { generalmente implica elegir una opción de entre varias que se presentan (ejemplo, } \\
\text { cuadro de diálogo). }\end{array}$ & \\
\hline $\begin{array}{l}\text { 13. Leer buscando } \\
\text { información específica }\end{array}$ & $\begin{array}{l}\text { Leer en la pantalla con el propósito de localizar una palabra, frase o información espe- } \\
\text { cífica (ejemplo, hacer clic en el nombre del archivo deseado). }\end{array}$ & \\
\hline 14. Leer para revisar & $\begin{array}{l}\text { Leer en la pantalla en voz alta o en silencio para revisar el trabajo en proceso. } \\
\text { Ocurre comúnmente para verificar si se está realizando bien el trabajo; otras } \\
\text { veces lleva a detectar errores de escritura o codificación. }\end{array}$ & \\
\hline 15. Señalar ortografía & $\begin{array}{l}\text { Hacer alusión a la ortografía o forma correcta de escribir una palabra. También se } \\
\text { incluyen errores de ortografía que se cometen, pero que no se repara en ellos, o } \\
\text { bien reconocer errores ortográficos por los subrayados en rojo que anuncia el } \\
\text { propio software. }\end{array}$ & \\
\hline 16. Codificar & $\begin{array}{l}\text { Escribir en pantalla códigos (no son copiados o dictados). Incluye borrar, copiar y } \\
\text { pegar. }\end{array}$ & \multirow{2}{*}{$\begin{array}{l}\text { Propios del entorno } \\
\text { computacional. }\end{array}$} \\
\hline 17. Negociar código & $\begin{array}{l}\text { Ponerse de acuerdo qué línea de código anotar o qué ajustes al código hacer, lo } \\
\text { que implica escribir signos, letras etc. }\end{array}$ & \\
\hline
\end{tabular}


critura; ocho más sufren ciertas modificaciones ya que no se asumen tal cual en los entornos computacionales, como por ejemplo formas distintas de leer en la pantalla, de escribir información cifrada y de corregir auxiliándose de la herramienta de ortografía y gramática; por último, codificar y ponerse de acuerdo en qué código anotar para lograr tal o cual resultado son usos específicos de las nuevas tecnologías.

Como se puede evidenciar, algunos son usos específicos del medio impreso, algunos otros pasan de forma directa al trabajar en la computadora, pero hay otros que se vuelven híbridos y otros más que surgen como formas específicas de las nuevas tecnologías computacionales. Esto último sugiere la presencia de prácticas multimodales que implican la conjugación de dos o más formas (Rassool, 1999). Es decir, para la producción textual se hace cada vez más uso deliberado de "modos representacionales y comunicativos que inciden en un mismo texto" (Kress, LeiteGarcía \& van Leewen, 1997, p. 257). De acuerdo con Kress (2003), la lectura electrónica es una lectura multimodal en la que la modalidad verbal sólo es una más, dado el carácter gráfico de la pantalla. Esta variedad de representaciones textuales incluye información impresa, en imágenes, y producen experiencias multisensoriales que nos exigen diferentes modos de leerlas y escribirlas. De manera que la lectura electrónica requiere un lector interpretativo más que simplemente de un decodificador (RodríguezIllera, 2003).

Para finalizar este apartado y con objeto de dimensionar los hallazgos antes descritos desde una perspectiva complementaria, se presenta la frecuencia con la que ocurren las prácticas de leer y de escribir referidas. En la Tabla 3 se agrupan, del lado izquierdo, las columnas con las díadas de alumnos con menor experiencia en entornos computacionales (básicos) y, del lado derecho, los de mayor experiencia (avanzados). Asimismo, se diferencian cuatro conjuntos de datos por renglones o filas: unos en tono gris y otros claros; cada bloque está organizado de mayor a menor frecuencia en los totales. Cabe señalar que el primero de estos cuatro bloques representa los usos de lengua escrita con mayor ocurrencia entre los

Tabla 3 - Frecuencia con que se presentan las prácticas de lectura y escritura

\begin{tabular}{|c|c|c|c|c|c|c|c|c|c|c|c|}
\hline \multirow[b]{2}{*}{ PRÁCTICAS } & Í́ADAS & \multicolumn{2}{|c|}{ Básicos } & \multicolumn{3}{|c|}{ Subt. } & \multicolumn{2}{|c|}{ Avanzados } & \multicolumn{2}{|r|}{ Subt. } & \multirow{2}{*}{ Totales } \\
\hline & I-J & C-M & Y-J & A-G & Básicos & A-L & D-I & E-C & E-M & Avanzados & \\
\hline Dictar-Escribir Texto & 4 & 40 & 13 & 32 & 89 & 0 & 0 & 1 & 0 & 1 & 90 \\
\hline Corregir & 3 & 22 & 9 & 23 & 57 & 1 & 1 & 4 & 5 & 11 & 68 \\
\hline Escribir & 6 & 4 & 16 & 0 & 26 & 8 & 12 & 3 & 3 & 26 & 52 \\
\hline Negociar texto & 15 & 5 & 3 & 0 & 23 & 0 & 0 & 12 & 7 & 19 & 42 \\
\hline Señalar ortografía & 7 & 14 & 4 & 0 & 25 & 0 & 0 & 3 & 2 & 5 & 30 \\
\hline Formatear texto & 4 & 10 & 10 & 2 & 26 & 0 & 0 & 0 & 2 & 2 & 28 \\
\hline Escribir en cuaderno & 19 & 0 & 0 & 0 & 19 & 5 & 0 & 0 & 3 & 8 & 27 \\
\hline Copiar & 0 & 4 & 2 & 1 & 7 & 0 & 3 & 0 & 1 & 4 & 11 \\
\hline $\begin{array}{l}\text { Leer buscando } \\
\text { información específica }\end{array}$ & 4 & 0 & 0 & 15 & 19 & 20 & 17 & 16 & 7 & 60 & 79 \\
\hline Leer para revisar & 1 & 12 & 8 & 3 & 24 & 1 & 7 & 13 & 18 & 39 & 63 \\
\hline Leer para comprender & & & & & & & & & & & \\
\hline información & 2 & 0 & 0 & 4 & 6 & 0 & 4 & 4 & 0 & 8 & 14 \\
\hline Leer y comentar & 1 & 1 & 0 & 0 & 2 & 0 & 1 & 5 & 3 & 9 & 11 \\
\hline Revisar-planear & 0 & 5 & 9 & 0 & 14 & 0 & 0 & 12 & 1 & 13 & 27 \\
\hline Reflexionar & 9 & 8 & 6 & 0 & 23 & 0 & 0 & 2 & 1 & 3 & 26 \\
\hline Codificar & 0 & 0 & 0 & 0 & 0 & 0 & 12 & 21 & 29 & 62 & 62 \\
\hline Negociar código & 0 & 0 & 0 & 0 & 0 & 0 & 0 & 13 & 11 & 24 & 24 \\
\hline Dictar-Escribir Código & 0 & 0 & 0 & 0 & 0 & 0 & 0 & 9 & 8 & 17 & 17 \\
\hline Totales & 75 & 125 & 80 & 80 & 360 & 35 & 57 & 118 & 101 & 311 & 671 \\
\hline
\end{tabular}

Clave: BÁSICOS: I-J: Ismael y Julián (barra de herramientas), C-M: Claudia y Miriam (resumen), Y-J: Yadira y Jazmín (horario de clases), A-G: Ariza y Gabriela (gráficas).AVANZADOS: A-L: Ángel y Luis (animaciones), D-I: David e Israel (página Web), E-C: Estela y Carla (página Web Mundial de Fútbol), E-M: Évelyn y Mariana (página Web de San Pedro Mártir). 
alumnos básicos, como son el dictado y la corrección de errores de escritura, en tanto que el último bloque corresponde únicamente a aquellos presentes entre los avanzados, como es la lectura en la pantalla para localizar información específica (nombres de archivos, opciones de menús, entre otros).

\section{Mediación tecnológica: expresión de continuidades, transformaciones e innovaciones al leer y escribir}

Las diferencias encontradas entre alumnos con mayor y menor experiencia en el uso de las computadoras remiten a los hallazgos recientes en estudios sobre el aprendizaje en entornos computacionales $(e$. g. Healy, Pozzi \& Hoyles, 1995; Hoyles \& Noss, 2003; Hoyles, Noss \& Kent, 2004). Estos trabajos sugieren que los alumnos que trabajan conjuntamente en la realización de una tarea de solución de problemas utilizando papel y lápiz se trazan una estrategia a la vez para abordar el problema, misma que ejecutan llevándola a término, es decir, agotan determinada estrategia hasta sus últimas consecuencias, verificando hasta el final si logran o no la solución. Para estos alumnos, sus representaciones son inertes en el sentido de que no tienen una forma inmediata de representar gráficamente sus acciones, no tienen una retroalimentación inmediata o medios certeros de validación de lo que están realizando. Es por ello que comúnmente agotan una estrategia, antes de probar la siguiente. Además, la validación de su ejecución es externa y por lo general proviene del maestro o maestra que supervisa su desempeño.

En contraparte, los alumnos que en lugar de lápiz y papel realizan la tarea de solución de problemas utilizando una computadora, el abordaje que hacen contrasta significativamente. El proceso de resolución es más dinámico, puesto que prueban diversas estrategias que de inmediato pueden ir verificando si funcionan o no, ya que sus representaciones no son inertes, sino tienen una retroalimentación inmediata de sus acciones, verificable en la propia computadora. Su trabajo es más independiente al no requerir de validación o retroalimentación externa del maestro o maestra, ya que la obtienen de la propia herramienta tecnológica que están utilizando.

Lo anterior ofrece una explicación plausible de lo que sucede en los estudiantes básicos y avanzados del presente estudio. Si consideramos que los primeros tienen como referente lo impreso, similar a los alumnos que trabajan con lápiz y papel, estos alumnos llevan a término la estrategia que tienen en mente, no teniendo otra representación de su trabajo más que un modelo impreso. Es por ello que Yadira y Jazmín difícilmente se atreven a probar opciones de la computadora, y prefieren comenzar hasta tres veces su tarea para insertar una tabla con el número correcto de celdas, en lugar de explorar el menú "Tabla" y probar las opciones de "insertar" o "eliminar" columnas, filas o celdas. Además, la validación de su tarea es externa por lo que una y otra vez buscan el auxilio de su maestra. Para los segundos, su referente es electrónico, como en el caso de alumnos que resuelven un problema usando la computadora. Es por ello que las animaciones que crean David e Israel las realizan de forma dinámica e independiente, nunca consultan al maestro o a otro compañero, sino que prueban opciones y verifican sus avances con representaciones inmediatas en la propia computadora, que activan al apretar la tecla Enter.

Por otra parte, los hallazgos apuntan hacia un entendimiento de la computadora como un "nuevo espacio de escritura" (en términos de Bolter, 1991, p. 10), del cual los alumnos se van apropiando conforme van adquiriendo mayor experiencia en su utilización y aprovechamiento, dando lugar a transformaciones en el ejercicio de sus prácticas de lectoescritura. Este autor arguye que el uso de la computadora, como en su momento ocurrió con las emergentes tecnologías de escritura de otras épocas, está reestructurando nuestra actual economía de la escritura. Esta tecnología permite al individuo contar con una nueva superficie para grabar y presentar textos con nuevas formas de organización al escribir. Esto es, para la escritura electrónica, el espacio es la pantalla de la computadora donde el texto se despliega 
como una memoria electrónica en la que se almacena el texto. El espacio de escritura/lectura es animado, visualmente complejo y en buena medida es manipulable por el escritor/lector. En este sentido, cada espacio físico de escritura/lectura propicia una particular forma de entender, tanto el acto de escribir como el producto escrito, es decir, el texto escrito. Aunque la tecnología electrónica nos ofrezca una nueva forma de libro y nuevas maneras de escribir y leer, de cualquier modo, como lo expresa Bolter, "escribir, utilizando cualquier medio, es un acto de apropiación" (p. 42), en el que el individuo expresa palabras e ideas que, utilizando las TIC, puede llevar fuera de su tiempo real y almacenarlas para su uso posterior.

La presente investigación se realizó con el propósito de explorar cuáles prácticas de lectura y escritura despliegan los alumnos al aprender a usar la computadora en la escuela y cuáles de ellas son propias o no de las nuevas tecnologías de la información y comunicación. Al buscar resolver tales planteamientos, la investigación llevó a dar cuenta de cuán distintas pueden ser las prácticas de lectura y escritura mediadas por el uso de las computadoras, en contraste con las prácticas que no utilizan dicho mediador cultural. Los alumnos en este estudio van demostrando como se apropian de este nuevo espacio de escritura, algunos haciendo mínimas modificaciones respecto a su habitual uso de la pluma y la libreta, otros incursionando en el aprovechamiento de las herramientas computacionales como la de "Sinónimos", u "Ortografía” y "Gramática”, algunas alumnas más ya van haciendo transforma-ciones de datos a gráficas, en tanto que las más avezadas llegan a dominar la forma de anotar códigos que transforman en presentaciones multimedia complejas, en las que la negociación conjunta del texto a desplegar en su página $W e b$ va acompañada de un lenguaje de programación sofisticado que conocen para que sirve, saben su sintaxis, así como la manera en que se transforma en su presentación en pantalla.

$\mathrm{Al}$ analizar desde una perspectiva sociocultural las formas distintas en las que los participantes hacen uso del lenguaje escrito y de la oralidad alrededor de los textos impresos y digitales, se aprecia que dichos usos están determinados por la situación específica en que los alumnos involucrados requieren utilizar el lenguaje escrito, al participar juntos en una producción concreta y con propósitos propios. La demanda de utilizar las nuevas tecnologías no exige solamente el leer y escribir en materiales impresos, sino ahora exige tener ciertas habilidades tecnológicamente funcionales, pero también la posibilidad de participar en un cierto tipo de discurso y, más aún, con la globalización que implica el uso de tales tecnologías, el uso de otro idioma como es el inglés, en el que están varios de los programas que utilizan estos alumnos. Las nuevas tecnologías están propiciando el acceso a mundos con múltiples formas de leer y escribir a partir de las que ya conocemos.

En la arena de la discusión acerca del tópico, se señaló al inicio la existencia de una discusión sobre cómo para algunos estudiosos del tema el uso de las TIC representan prácticas lectoescritoras totalmente distintas a las que se usan sin estas tecnologías (Selfe y Hilligoss, 1994), en tanto que otros señalan que principalmente son la rapidez y conectividad los auxiliares en la mejor presentación y organización de trabajos escritos (Yagelski, 2000). Si bien en el continuo de posturas a este respecto se detecta que con el advenimiento y avance de las TIC ciertas formas de leer y escribir se han transformado y otras nuevas han emergido, este estudio ha podido develar algunas de estas transformaciones. A partir de los hallazgos, lo que se puede afirmar es que lo impreso y lo electrónico conviven y comparten un mundo denso de mensajes gráficos de todo tipo. Algunos aspectos de la evolución del papel a la pantalla hacen pensar que, más que una ruptura, existe una continuidad y transformación de la cultura escrita. Como se pudo constatar, ciertas prácticas lectoescritoras se mantienen, otras se transforman y otras más son nuevas.

Asimismo, los presentes hallazgos indican que entre la página y la pantalla existe una relación de complementariedad y no de exclusión. Observamos que la pluma, el libro y la computadora coexisten, al igual que el pizarrón, la libreta de apuntes y la pantalla. 
Ello coincide con la idea desarrollada por Street (1995) y Graff (1987) de como las prácticas sociales emergen en un contexto específico y se transforman con el tiempo. Dicha perspectiva permite ahora revisar, con un ojo más crítico, las diferentes posiciones en el campo acerca del impacto de la computadora y la comunicación mediada sobre los textos impresos, su permanencia o extinción. También nos permite ver con más claridad las prácticas de lectura y escritura en la pantalla y la página. Si bien hay indicios de que estamos en una transición hacia el ocaso del libro, no lo sabremos hasta llegar al otro lado del proceso. Lo que sí podemos constatar es que, por ahora, nos encontramos viviendo en un mundo inundado de materiales impresos.

Una de las preocupaciones planteadas en los estudios referidos en la introducción ha sido examinar las formas en que las TIC pueden favorecer las prácticas de lectura y escritura o utilizar sus recursos para propiciar el aprendizaje formal de contenidos educativos (Anderson-Inman \& Horney, 1998; Labbo \& Kuhn, 1998; Spiro \& Jehng, 1990). A este respecto, se puede reconocer que las prácticas de lengua escrita incorporan cada vez más la utilización de las computadoras como manifestación de las nuevas tecnologías de la comunicación y la información en las escuelas. Las computadoras constituyen una herramienta tecnológica considerada como una forma relativamente nueva de interactuar con los textos escritos, y con un gran potencial como apoyo a la enseñanza. Pero el problema educativo central no se puede limitar a la página o a la pantalla sin fomentar el desarrollo de la lectura y la escritura entre los alumnos, propiciando que sean lectores críticos y versátiles, así como escritores creativos y competentes. Ello significa enseñar a comprender lo que se lee y reconocer la diferencia entre obtener información y analizarla, organizarla y evaluarla. No hay que perder de vista que, después de todo, la computadora no enseña cómo leer/escribir electrónicamente (Kalman, 2001).

Ya refería Cassany (2003b) que existen numerosos programas de computación que auxilian en la lectura y escritura, con rapidez y eficacia en el formateo, legibilidad y ortografía; no obstante, retomando las concepciones de Rodríguez-Illera (2003) sobre leer con la pantalla (en lugar de leer de la pantalla), el presente estudio apunta hacia una mayor reflexión en el sentido de Anderson (2001) sobre considerar que las TIC no deben ser un fin en sí mismo, sino una herramienta flexible que se utilice para atender necesidades específicas en contextos de aprendizaje claramente definidos. Como se demostró aquí, las prácticas lectoescritoras que despliegan los alumnos se modifica conforme a la producción que realizan y el conocimiento sobre los programas que se requieren para concretarla. Las propuestas educativas bien podrían considerar estos aspectos al momento de diseñar estrategias instruccionales que fomenten un uso de la lengua escrita mediada por las TIC, más creativo, crítico y competente. No se trata sólo de enseñar como usar esta tecnología, sino como leer/escribir competitivamente aprovechando los recursos que ofrecen las TIC.

Se considera a la luz de este estudio que un cambio provisto por el uso de las TIC está también en la conceptualización de lo que significa leer y escribir para el usuario, ya que cambia el punto de vista del escritor, al entender el texto electrónico como una red de elementos verbales, y el punto de vista del lector, quien tiene ahora una estructura con diversas formas posibles de lectura. Este cambio de concepción debiera hacerse explícito en el contexto educativo con la finalidad de auxiliar a conducir al lector/escritor a ir desarrollando prácticas que satisfagan sus propósitos concretos de leer y escribir, llevándolo a examinar la vasta gama de textos disponibles vía la computadora y la conectividad, a hacer búsquedas efectivas de información, a recuperar aquello que le sea significativo, y a producir textos organizados en una propia red textual que le pertenezcan como un propio individuo o comunidad, y a una particular forma de leer y escribir.

Sin lugar a dudas hace falta incluir en la agenda de investigación más estudios que lleven a revisar la conceptualización de la lengua escrita a la luz de las TIC, y qué aspectos de ellas adquieren relevancia para 
El desplazamiento de prácticas impresas y la apropiación de prácticas digitales

la cultura escrita, ya que se trata de tecnologías que continúan en rápido desarrollo dando lugar no precisamente a la sustitución de las anteriores, sino a la generación de nuevas aplicaciones de las mismas. Faltan más estudios sobre los procesos involucrados en la lectura de hipertextos (Cassany, 2003b; Kamil \& Lane, 1998), que tan similares son a aquéllos desplegados al leer textos convencionales, e incluso, si se debieran desarrollar nuevas metodologías para este tipo de investigación. Nuevos hallazgos en este ámbito sin duda ayudarán en la toma de decisiones informada acerca de cuáles prácticas tienen mayores probabilidades de éxito en hacer a un individuo un ser alfabetizado.

\section{Referencias bibliográficas}

ANDERSON, A. B.; TEALE, W. B.; ESTRADA, E. Low income children's preschool literacy experiences: Some naturalistic observations. The Quarterly Newsletter of the Laboratory of Comparative Human Cognition, v. 2, n. 3, p. 59-65, 1980.

ANDERSON, J. Web publishing in non-roman scripts: effects on the writing process. Language and Education, v. 15, n. 4, p. 229249, 2001.

ANDERSON-INMAN, L.; HORNEY, M. Transforming text for at-risk readers. In: REINKING, D.; McKENNA, M.; LABBO, L.; KIEFFER, R. (Eds.). Handbook of literacy and technology. Transformations in a post-typographic world. Mahwah, NJ: Lawrence Erlbaum Associates, Inc., 1998.

BARTON, D. Literacy. An Introduction to the Ecology of Written Language. Oxford: Blackwell, 1994.

BOLTER, J. D. Writing space. The computer, hypertext and the history of writing. Hillsdale, NJ: Lawrence Erlbaum Associates, Inc., Publishers, 1991.

CASSANY, D. La lectura electrónica. Cultura y Educación, v. 15, n. 3, p. 239-251, 2003a.

Presentación. Cultura y Educación, v. 15, n. 3, p. 221224, 2003b.

COSTANZO, W. Reading, writing, and thinking in an age of electronic literacy. In: SELFE, C. L.; HILLIGOSS, S. (Eds.). Literacy and computers. The complications of teaching and learning with technology. New York: The Modern Language Association of America, 1994.

DORR, A. What constitutes literacy in a culture with diverse and changing means of communication? In: KELLER-COHEN, D. (Ed.). Literacy: Interdisciplinary conversations. Cresskill, NJ: Hampton Press Inc., 1994.

GEE, J. Social linguistics and literacies. Gran Bretaña: Falmer Press, 1996.

GRAFF, J. C. The legacies of literacy. Continuities and contradictions in western culture and society. Bloomington and Indianapolis: Indiana University Press, 1987.

GRAY, W. S. The teaching of reading and writing. Paris: UNESCO, 1956.

HAWISHER, G.; SELFE, C. Reflections on computers and composition studies at the century's end. In: SNYDER, I. (Ed.). Page to screen. Talking literacy into the electronic era. London: Routledge, 1998.

HEALY, L.; POZZI, S.; HOYLES, C. Making sense of groups, computers and mathematics. Cognition and Instruction, v. 13, n. 4 , p. 505-523, 1995.

HEATH, S. B. Ways with words. Cambridge: Cambridge University Press, 1983.

HOYLES, C.; NOSS, R. What can digital technologies take from and bring to research in mathematics education? In: BISHOP, A. J.; CLEMENTS, M. A.; KEITEL, C.; KILPATRICK, J.; LEUNG, F. K. S. (Eds.). Second international handbook of mathematics education. Dordrecht: Kluwer Academic Publishers, 2003.

HOYLES, C.; NOSS, R.; KENT, P. On the integration of digital technologies into mathematics classrooms. International Journal of Computers for Mathematical Learning, v. 9, p. 309326, 2004.

HYNES, C. Prosthetic-rhetoric writing.loss.technology. In: TAYLOR, T.; WARD, I. (Eds.). Literacy theory in the age of Internet. New York: Columbia University Press, 1998.

KALMAN, J. Las prácticas de lectura y escritura frente a las nuevas tecnologías de comunicación e informática. In: MATUTE, E.; ROMO, M. (Eds.). Los retos de la educación del siglo XXI. México: Universidad de Guadalajara, 2001. ¿Somos lectores o no? Una revisión histórica del concepto de alfabetización y sus consecuencias. In: SCHMELKES, 
S. (Comp.). Lecturas para la educación de los adultos. México: INEA-Noriega Editores, 2000. v. 4.

KAMIL, M.; LANE, D. Researching the relation between technology and literacy: An agenda for the $21^{\text {st }}$ Century. In: REINKING, D.; McKENNA, M.; LABBO, L.; KIEFFER, R (Eds.). Handbook of literacy and technology. Transformations in a posttypographic world. Mahwah, NJ: Lawrence Erlbaum Associates, Inc., 1998.

KAPLAN, N.; MOULTHROP, S. Something to imagine: Literature, composition, and interactive fiction. Computers and Composition, n. 9, p. 7-23, 1991.

KRESS, G. Literacy in the new media age. London: Routledge, 2003.

KRESS, G.; LEITE-GARCÍA, R.; van LEEWEN, T. Discourse semiotics. In: van DIJK, T. (Ed.). Discourse as structure and process. Londres: Sage, 1997.

LABBO, L. D. A semiotic analysis of young children's symbol making in a classroom computer center. Reading Research Quarterly, v. 31, n. 4, p. 356-385, 1996.

LABBO, L. D.; KUHN, M. Electronic symbol making: Young children's computer-related emerging concepts about literacy. In: REINKING, D.; MCKENNA, M.; LABBO, L.; KIEFFER, R. (Eds.). Handbook of literacy and technology. Transformations in a post-typographic world. Mahwah, NJ: Lawrence Erlbaum Associates, Inc., 1998.

LANKSHEAR, C.; SNYDER, I.; GREEN, B. Teachers and technoliteracy. Managing literacy, technology and learning in schools. Australia: Allen \& Unwin, 2000.

MATTHEW, K. I. The impact of CD-ROM Storybooks on children's reading comprehension and reading attitude. Journal of Educational Multimedia and Hypermedia, v. 5, n. 3/4, p. 379-94, 1996.

McKENNA, M. C. Electronic texts and the transformation of beginning reading. In: REINKING, D.; MCKENNA, M.; LABBO, L.; KIEFFER, R. (Eds.). Handbook of literacy and technology. Transformations in a post-typographic world Mahwah, NJ: Lawrence Erlbaum Associates, Inc., 1998.

NÁJERA, O. M. Artefactos culturales y alfabetización: del papel al ordenador en una comunidad mestiza. Comunicación, Lenguaje y Educación, v. 13, n. 1, p. 37-58, 2001.
NOSS, R.; HOYLES, C. Windows on mathematical meaning. Learning cultures and computers. Dordrecht: Kluwer Academic Publishers, 1996.

RASSOOL, N. Literacy for sustainable development in the age of information. Londres: Multilingual Maters Ltd., 1999.

RODRÍGUEZ-ILLERA, J. La lectura electrónica. Cultura y Educación, v. 15, n. 3, p. 225-37, 2003.

SAlOMON, G. Distributed cognition. Psychological and educational considerations. Nueva York. Cambridge University Press, 1993b.

On the nature of pedagogic computer tools. Hillsdale,

NJ: Lawrence Erlbaum Associates, Inc. Publishers, 1993a.

SALOMON, G.; PERKINS, D. N.; GLOBERSON, T. Coparticipando en el conocimiento: la ampliación de la inteligencia humana con las tecnologías inteligentes. Comunicación, Lenguaje y Educación, n. 13, p. 6-22, 1992.

SELFE, C. L.; HILLIGOSS, S. Introduction. In: SELFE, C. L.; HILLIGOSS, S. (Eds.). Literacy and computers. The complications of teaching and learning with technology. New York: The Modern Language Association of America, 1994.

SPIRO, R. J.; JEHNG, J. Cognitive flexibility theory and hypertext: theory and technology for the nonlinear and multidimensional traversal of complex subject matter. In: NIX, D.; SAPIRO, R. (Eds.). Cognition, education, and multimedia: Exploring ideas in high technology. Hillsdale, NJ: Lawrence Erlbaum Associates, Inc. Publishers, 1990.

STREET, B. Introduction: The new literacy studies. In: STREET B. V. (Ed.). Cross-cultural approaches to literacy. Cambridge: Cambridge University Press, 1993.

Literacy in theory and practice. Cambridge:

Cambridge University Press, 1984.

The meanings of literacy. In: WAGNER, D.;

VENEZKY, R.; STREET, B. (Eds.). Literacy: an international handbook. Boulder: Westview Press, 1999.

Recent application of new literacy studies in educational context. Research in the Teaching of English, v. 39, n. 4, p. 417-23, 2005.

Social literacies: Critical approaches to literacy in development, ethnography and education. London: Longman, 1995.

Revista Brasileira de Educação $\quad$ v. 11 n. 31 jan./abr. 2006 
El desplazamiento de prácticas impresas y la apropiación de prácticas digitales

SULZBY, E. Writing and reading: Signs of oral and written language organization in the young child. In: TEALE, W. H.; SULZBY, E. (Eds.). Emergent literacy: Writing and reading. Norwood, NJ: Ablex, 1986.

YAGELSKI, P. R. Literacy matters, writing and reading the social self. Nueva York y Londres: Teachers College, Columbia University, 2000.

LAURA MACRINA GÓMEZ ESPINOZA, maestra en psicología educativa por la Universidad Nacional Autónoma de México (UNAM), actualmente está finalizando un Doctorado en Investigaciones Educativas, que otorga el Departamento de Investigaciones Educativas, del Centro de Investigación y de Estudios Avanzados (CINVESTAV), del Instituto Politécnico Nacional, México. Diseña y desarrolla contenidos curriculares y sistemas de evaluación del aprendizaje a nivel bachillerato, licenciatura y posgrado, para el Instituto de Investigación de Tecnología Educativa, de la Universidad Tecnológica de México. Colabora como investigadora del Laboratorio de Cognición y Comunicación, de la Facultad de Psicología de la UNAM, donde ha participado en diversos estudios sobre comprensión y producción escrita, interacción y discurso, así como construcción social del conocimiento, en escenarios educativos de enseñanza primaria.
Sus publicaciones más recientes son: con Sylvia Rojas-Drummond, Dialogue for reasoning: promoting exploratory talk and problem solving in the primary school (In: WARDEKKER, W.; ELBERS, E.; van der VEER, R.; van OERS, B. (Eds.). The transformation of learning. Cambridge: Cambridge University Press. En imprenta); Talking for reasoning among Mexican primary school children (Learning and Instruction, n. 13, p. 653-670, 2003); y El desarrollo de macroestructuras en niños de primaria (Estudios de lingüística aplicada. México: UNAM, 2000). También ha realizado varias contribuciones con reseñas de publicaciones latinoamericanas en el campo de la cultura escrita con Judith Kalman, Annotated bibliography of research in the teaching of English (Research in the Teaching of English, n. 37, p. 527-537, 2003; Research in the Teaching of English, n. 36, p. 287-295, 2001; Research in the Teaching of English, n. 25, p. 261-272, 2000). Actualmente se orienta a la investigación de la cultura escrita y su mediación con las nuevas tecnologías de la comunicación y la información, incluyendo metodologías cualitativas y cuantitativas. E-mail: lmacrina@yahoo.com
Recebido em outubro de 2005 Aprovado em dezembro de 2005 
cola ainda privilegiar a "cognição", os jovens estudantes não se interessam tanto pelos conteúdos e temas de estudos como pelas relações que se estabelecem (ou podem ser estabelecidas) no ambiente escolar, mediadas por tecnologias da comunicação. Neste artigo, pretendo, inicialmente, refletir sobre as relações entre a ação educativa escolar e as tecnologias, para, num segundo momento, mostrar como chegar a um processo de formação docente na escola, com o uso dos meios de comunicação. Referimo-me a um conjunto de procedimentos e meios tecnológicos que põem em discussão questões individuais, referentes aos interesses e subjetividades dos sujeitos, e questões sociais, referentes aos ambientes socioculturais dos quais os indivíduos participam. A escola e os meios tecnológicos de comunicação assemelham-se porque tratam da realidade e ambos são local de aquisição de saberes; assim, educar com os meios e educar para os meios é imprescindível à educação escolar por possibilitar um ambiente favorável à cotidianidade.

Palavras-chave: tecnologias; meios de comunicação; linguagens na escola

Technologies of communication and information in schools: possible relation... constructed relations We are facing new ways of understanding, perceiving, feeling and learning within which affection, imagination and values cannot be left aside. Although school still highlights "cognition", the young students are not so much interested in the contents and themes of their studies, as much as they are interested in the relationships that are (or can be) established in the school environment, mediated by technologies of communication. In this paper, initially, I intend to reflect upon the relations between school educational action and technology, to show, later on, how I have devised a process of teacher training in schools with the help of the media. I am referring to a set of procedures and technological means which put in discussion individual questions, related to the interests and the subjectivity of individuals, and to social questions, related to the socio-cultural environments in which individuals participate. The school and the technological means of communication are similar inasmuch as they both deal with reality and are place for acquiring knowledge; thus, to educate with the media and for the media is indispensable for school education because it allows the creation of an favourable environment to daily life.

Key-words: technology; communication media; languages in school

Las tecnologías de comunicación e información en la escuela; relaciones posibles... relaciones construídas

Estamos delante de nuevas maneras de comprender, de percibir, de sentir y de aprender, en las cuales, la afectividad, la imaginación y los valores no pueden dejar de ser considerados. A pesar de la escuela todavía privilegiar la “cognición”, los jóvenes estudiantes no se interesan tanto por los contenidos y temas de estudios como por las relaciones que se establecen (o pueden ser establecidas) en el ambiente escolar, mediadas por las tecnologías de la comunicación. En este artículo, pretendo, inicialmente, reflexionar sobre las relaciones entre la acción educativa escolar y las tecnologías, para, en un segundo momento, mostrar como llegar a un proceso de formación docente en la escuela, con el uso de los medios de comunicación. Me refiro a un conjunto de procedimientos y medios tecnológicos que ponen en discusión cuestiones individuales, alusivos a los intereses y subjetividades de los sujetos y cuestiones sociales, referentes a los ambientes socioculturales de los cuales los individuos participan. La escuela y

los medios tecnológicos de

comunicación se asemejan, porque

tratan de la realidad y ambos son

locales de adquisición de saberes; así, educar con los medios y educar para

los medios es imprescindible a la

educación escolar, por posibilitar un

ambiente favorable a la cotidianidad.

Palabras claves: tecnologías; medios de comunicación; lenguajes en la escuela

Laura Macrina Gómez Espinoza

El desplazamiento de prácticas impresas y la apropiación de prácticas digitales. Un estudio con alumnos del bachillerato tecnológico aprendiendo a usar la computadora en la escuela

Se presenta una investigación cualitativa con perspectiva sociocultural sobre las prácticas lectoescritoras de ocho díadas de estudiantes de bachillerato tecnológico, al realizar tareas escolares utilizando la computadora. Se analizan datos recopilados mediante observación participante utilizando grabaciones en audio y video, lo que lleva a reconocer distintas prácticas de lectoescritura a partir del tipo de producción y conocimiento de los programas computacionales que se requieren para su realización. Los hallazgos revelan que tales prácticas se van transfigurando de lo impreso hacia lo digital conforme las producciones se tornan más complejas, y se ponen en práctica conocimientos y acciones más sofisticadas. Se concluye que las tecnologías de información y comunicación están propiciando el acceso a mundos con múltiples formas de leer y escribir, apuntado hacia una relación de complementariedad con el mundo impreso; esto lleva a reconsiderar el papel de la educación en la formación de lectores/escritores críticos, versátiles, creativos y competentes. 
Palabras claves: prácticas de lectura y escritura; tecnologías de información y comunicación; computadoras; estudiantes de enseñanza media superior; aproximación sociocultural; investigación cualitativa

O deslocamento de práticas impressas e a apropriação de práticas digitais.

Um estudo com alunos do ensino médio tecnológico aprendendo a usar o computador na escola

São apresentados os resultados de um projeto de pesquisa qualitativa centrado nas práticas de leitura e escrita de oito pares de alunos de ensino médio, que usam o computador. Com uma abordagem sociocultural, este trabalho analisa eventos alfabetizadores gravados em áudio e vídeo. As descobertas revelam como os alunos desenvolvem diversas práticas de leitura e escrita dependendo do tipo de produção e conhecimento que se requer para sua realização. Também explica como suas práticas são transformadas em processos de mudança do ambiente impresso para culturas digitais. $O$ estudo conclui que as tecnologias da informação e comunicação abrem as portas para mundos com múltiplas formas de ler e escrever, numa relação complementar com o mundo impresso. Esta situação leva a considerar o papel da educação na formação de leitores/ escritores críticos, versáteis, criativos e competentes.

Palavras-chave: práticas de leitura e escrita; tecnologias de informação e comunicação; computadores; estudantes do ensino médio; contexto sociocultural; pesquisa qualitativa

The substitution of printed practices and the appropriation of digital practices: a study of students of the technological baccalaureate learning to use computers at school Presents a qualitative research on the literacy practices of eight dyads of high school students, whom use the computer to accomplish their school tasks. The article analyses literacy events recorded in audio and videotape from a sociocultural perspective. It reveals that the students develop different literacy practices according to the kind of production and knowledge of softwares needed to accomplished their school tasks. It concludes that the new technologies of communication provide access to worlds of multiple ways of reading and writing, based on those we already know, but that education should not omit its role in the formation of critical and competent readers and creative and versatile writers; after all, computers do not teach how to read and write electronically.

Key-words: literacy practices; ICT; computers; high school students; sociocultural approach; qualitative research

Marcos Cezar de Freitas

Economia e educação: a contribuição de Álvaro Vieira Pinto para o estudo histórico da tecnologia Este artigo analisa a contribuição de Álvaro Vieira Pinto para os estudos de economia e educação. Seu conceito de trabalho tecnologicamente elaborado pode ser reconhecido como resultado de uma profunda investigação sobre as relações humanas que encontramos na "cultura da economia". Seu caminho teórico até os escritos de Marx aponta uma capacidade erudita de relacionar educação e emancipação política com a história da tecnologia.

Palavras-chave: economia; educação; tecnologia; cultura

Economy and education: Álvaro Vieira Pinto's contribution to historical studies on technology This paper analyses Álvaro Vieira Pinto's contribution to studies on economy and education. His concept of technologically elaborated work should be understood as the result of profound research into human relations which we find in the "culture of economics". His theoretical encounter with Marx's writings reveals an erudite capacity to relate education and political emancipation with the history of technology.

Key-words: economy; education; technology; culture

Economía y educación: la contribución de Álvaro Vieira Pinto para el estudio histórico de la tecnología

Este artículo analiza la contribución de Álvaro Vieira Pinto para los estudios de economía y educación. Su concepto de trabajo tecnológicamente elaborado puede ser reconocido como resultado de una profunda investigación sobre las relaciones humanas que encontramos en la "cultura de la economía". Su camino teórico hasta los escritos de Marx, muestran una capacidad erudita de relacionar educación y emancipación política con la historia de la tecnología.

Palabras claves: economía; educación; tecnología; cultura

Ana Waleska P. C. Mendonça, Libânia Nacif Xavier, Vera Lucia Alves Breglia, Miriam Waidenfeld Chaves, Maria Teresa Cavalcanti de Oliveira, Cecília Neves Lima, Pablo S. M. Bispo dos Santos

Pragmatismo e desenvolvimentismo no pensamento educacional brasileiro dos anos de 1950/1960 $\mathrm{O}$ artigo analisa as formas de apropriação do ideário da Escola Nova no Brasil, particularmente do pragmatismo deweyano, nos anos de 1950/1960. Parte-se do pressuposto de que a ideologia desenvolvimentista que pontuou o debate em torno da reestruturação econômica, política e social do país nessas duas décadas constituiu-se em um solo fértil para a retomada e a expansão do ideário pragmatista entre os educadores brasileiros, articulando-se, de forma al- 